\title{
TEAM IDENTITY AND PERFORMANCE-BASED COMPENSATION EFFECTS ON PERFORMANCE
}

\author{
A Dissertation \\ by \\ JANELL LEIGH BLAZOVICH
}

\author{
Submitted to the Office of Graduate Studies of \\ Texas A\&M University \\ in partial fulfillment of the requirements for the degree of \\ DOCTOR OF PHILOSOPHY
}

August 2008

Major Subject: Accounting 


\title{
TEAM IDENTITY AND PERFORMANCE-BASED COMPENSATION EFFECTS ON PERFORMANCE
}

\author{
A Dissertation \\ by \\ JANELL LEIGH BLAZOVICH
}

\author{
Submitted to the Office of Graduate Studies of \\ Texas A\&M University \\ in partial fulfillment of the requirements for the degree of \\ DOCTOR OF PHILOSOPHY
}

\begin{abstract}
Approved by:
Chair of Committee, Marjorie K. Shelley

Committee Members, Michael Kinney

Mary Lea McAnally

Victor Willson

Christopher Wolfe

Head of Department, James Benjamin
\end{abstract}

August 2008

Major Subject: Accounting 


\author{
ABSTRACT \\ Team Identity and Performance-based Compensation Effects \\ on Performance. (August 2008) \\ Janell Leigh Blazovich, B.S., Marquette University; \\ M.B.T., University of Minnesota \\ Chair of Advisory Committee: Dr. Marjorie K. Shelley
}

This study investigates whether team members work harder and perform better when they are compensated based on both team and individual performance than when compensated based on team or individual performance alone and whether teammates' familiarity with one another influences the effectiveness of the compensation scheme. Four-member ad hoc student teams repeatedly complete an interdependent task on the computer in an experiment in which I manipulate individual compensation plan (flat wage or performance-based incentives), team compensation plan (flat wage or performance-based incentives), and teammate familiarity (identified teammates with preexperiment interaction - strong id or unidentified teammates with no pre-experiment interaction - weak id). Results indicate that while the combination of team and individual performance-based compensation results in the highest performance, the incremental performance boost is higher from the first performance-based reward strategy, regardless of whether it is team or individual. Under both strong and weak identity, offering a combination of individual and team performance-based 
compensation results in comparable performance, suggesting that lower productivity levels associated with low team identity can be overcome with performance-based compensation. Together these results suggest that, regardless of team identity, firms can benefit from offering both team and individual performance-based compensation. However, companies should understand that the performance bump may be smaller from the second performance-based scheme. 


\section{DEDICATION}

I would like to dedicate this dissertation to several important people in my life.

To my daughter Marjorie, your smiles, laughter, hugs and kisses made this whole process more bearable. I love you!

To my Mom, who practically took up a second residence in Texas after Mari was born. You gave up your own life over and over and over again, to help make mine easier. And to my Dad, who helped me both financially and emotionally make it through this program. Thank you Mom and Dad!

And finally, to my "schoolfriends," who through this process became some of my best friends. I am going to miss you guys! 


\section{ACKNOWLEDGEMENTS}

This paper has benefitted from comments and suggestions from my dissertation committee (listed alphabetically): Mike Kinney, Mary Lea McAnally, Marjorie Shelley (Chair), Vic Willson, and Chris Wolfe. I thank John Lere, Diane Matson, Tom Omer, and Terrance Pitre for their helpful comments on earlier drafts. I also thank workshop participants at the University of Wisconsin - Eau Claire, St. Cloud State University, the University of St. Thomas, and Texas A\&M University. Remaining errors are my own. 


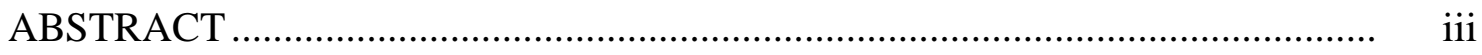

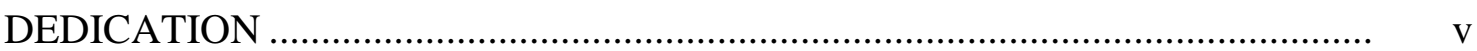

ACKNOWLEDGEMENTS ………………………..................................... vi

TABLE OF CONTENTS ..................................................................... vii

LIST OF FIGURES ................................................................................. ix

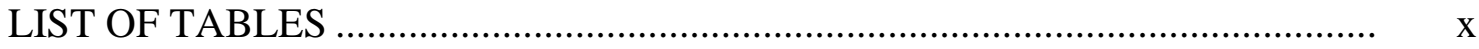

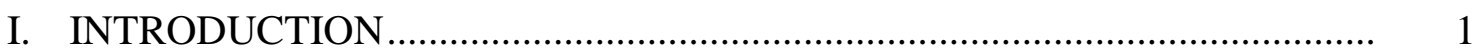

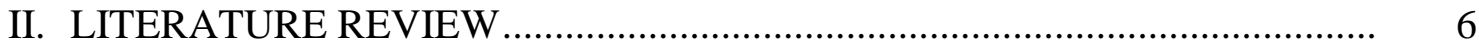

Teams and Performance ...........................................................................

Individual Compensation and Performance ................................................. 9

Team Compensation and Performance ....................................................... 10

III. BACKGROUND AND HYPOTHESIS DEVELOPMENT …………................ 15

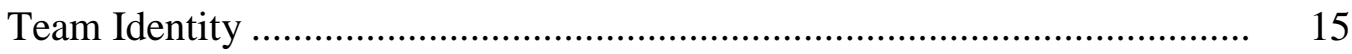

Performance-based Compensation ............................................................... 16

IV. RESEARCH METHOD .................................................................... 28

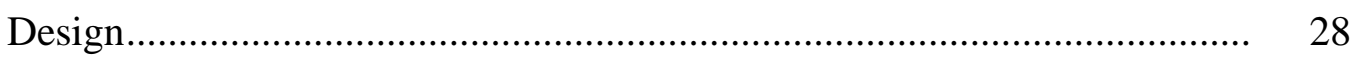

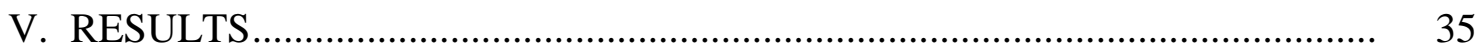

Manipulation Checks.............................................................................. $\quad 35$

Descriptive Results ………………………………………………...... 37

Replication Tests .................................................................................. 41

Hypotheses Tests ……………………………………………………..... 43

VI. DISCUSSION AND CONCLUSION …………………............................ 52 


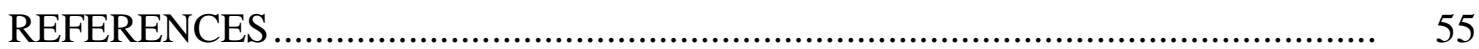

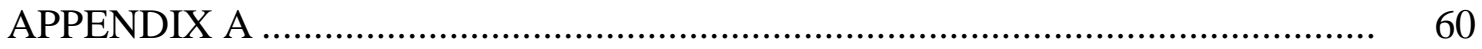

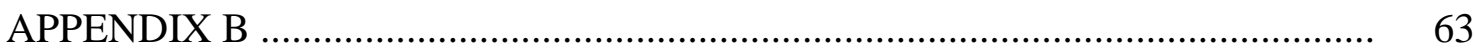

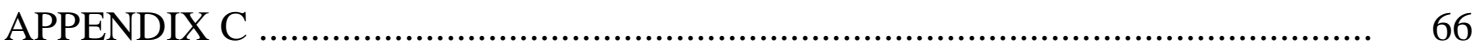

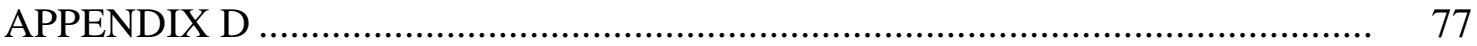

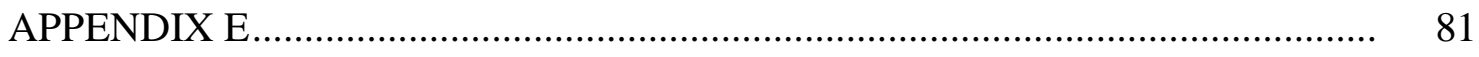






\section{LIST OF FIGURES}

Page

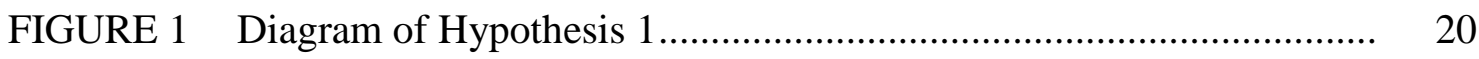

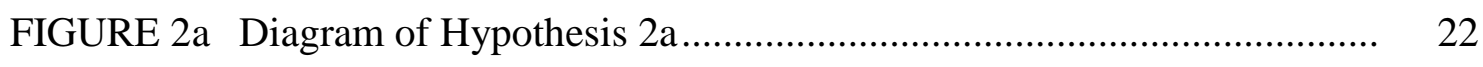

FIGURE 2b Diagram of Hypothesis 2b..................................................... 23

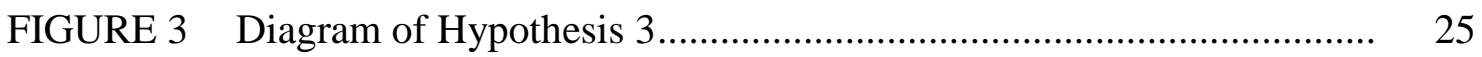

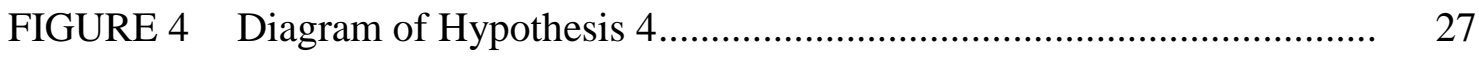

FIGURE 5 Interaction Effect between Individual Compensation and Team Identity on Estimated Mean Individual Output: Results for

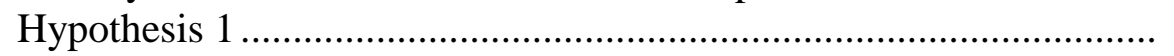

FIGURE 6 Interaction Effect between Team Compensation and Team Identity on Estimated Mean Individual Output: Hypotheses 2a and 2b ......... 46

FIGURE 7 Interaction Effect between Team Compensation and Individual Compensation on Estimated Mean Individual Output: Hypothesis 3.

FIGURE 8 Interaction between Individual and Team Compensation on Estimated Mean Individual Output by Team Identity: Hypothesis $4 \mathrm{a}$ and $4 \mathrm{~b}$ 


\section{LIST OF TABLES}

Page

TABLE $1 \quad$ Demographic Data....................................................................... 29

TABLE 2 Descriptive Statistics by Condition ............................................ 38

TABLE $3 \quad$ Results from Three ANOVAs with Repeated Measures.................... 42 


\section{INTRODUCTION}

This study investigates whether team members work harder and perform better when they are compensated based on both team and individual performance than when compensated based on team or individual performance alone and whether teammates' familiarity with one another influences the effectiveness of the compensation scheme. Understanding the joint impact of team and individual performance-based compensation schemes on effort and performance is important because although companies often are advised to offer a combination of team and individual performance-based compensation to provide incentives for team members to work toward common goals with a minimum of free-riding (Gary 1997a; Gary 1997b), little is known about possible interactions between team and individual performance plans. ${ }^{1}$ Studying the simultaneous effects of team and individual compensation plans, in contrast to studying each in isolation, better matches firms' actual compensation policies (Ehrenberg and Milkovich 1987; DeMatteo et al. 1998).

Team projects and team-based incentive plan use has increased (DeMatteo et al. 1998; DeZoort et al. 2000; Opdyke 2004; Rynes et al. 2005; Whitehouse 2005; Stiffler 2006), yet little empirical research examines the impact of team incentives on performance, either alone or in combination with individual incentive plans. Towry (2003) and Rankin (2004) are exceptions and both suggest that team incentives improve performance. Rankin examines the separate effects of individual and team performance-

This dissertation follows the style of The Accounting Review.

\footnotetext{
${ }^{1}$ One exception being Irlenbusch and Ruchala (2008) which finds that adding tournament style individual compensation to team compensation reduces teammate cooperation.
} 
based compensation, but never their combined effect. I extend Rankin (2004) by exploring the joint on effort and performance effect of providing both team and individual performance-based compensation.

Work team composition can vary in a number of ways - team member permanence (vs. ad hoc teams), team member geographic location, or team member functional specialization. Some work teams are composed of colleagues who know one another well and are assigned to work together to accomplish a project. Other teams are composed of virtual strangers working at different locations, assigned the task of jointly accomplishing a project. For example, the audit teams of large multi-location companies often use staff from local offices, who may never meet the audit manager, to perform inventory counts at satellite facilities. ${ }^{2}$ Similarly, audit and tax teams often require technological support from computer staff (e.g., converting client mainframe data into a pc-readable format) who may never meet the other team members. ${ }^{3}$ Therefore, I also investigate whether teammate familiarity (team identity) moderates the effect of performance-based compensation schemes.

Prior research finds teammate familiarity positively associated with effort and performance (Goodman and Leyden 1991; Gruenfeld et al. 1996; Cohen and Bailey 1997; Wech et al. 1998; De Cremer and van Vugt 1999; De Cremer and van Dijk 2002; King 2002; Towry 2003). Towry (2003) finds that when team identity is strong, within group monitoring systems are more effective than hierarchical monitoring systems at

\footnotetext{
${ }^{2}$ I thank Janet McDonald for this example from her work experience at Deloitte and Touche.

${ }^{3}$ This example is taken from my work experience at both The Profit Recovery Group and PricewaterhouseCoopers.
} 
inducing cooperation. I extend Towry (2003) by investigating whether team identity also influences effort and performance directly and whether it influences the effectiveness of team or individual compensation plans.

To eliminate task, compensation, and other incentives variation, I study my research question using a laboratory experiment in which I manipulate individual compensation plan (flat wage or performance-based incentives), team compensation plan (flat wage or performance-based incentives), and teammate familiarity (identified teammates with pre-experiment interaction - strong id or unidentified teammates with no pre-experiment interaction - weak id), all between subjects. ${ }^{4}$ Participants are randomly assigned to four-person teams, each of which loads four trucks each period, for 21 periods. Each teammate selects both a team and a solo effort level by choosing between 0 and 100 effort units for each effort type. Solo effort loads only a participant's own truck; team effort helps to load teammates' trucks; both effort types are costly (see Rankin 2004).

Participants' objective is to maximize earnings, which is compensation (based on outcome in some conditions) less effort costs. Achieving optimal output requires that all teammates provide both some solo and some team effort, making the task an interdependent one (Latane et al. 1979; Watson et al. 1991; Bacon et al. 1998). Earnings

\footnotetext{
${ }^{4}$ This results in an eight cell design with the following conditions: (1) strong id/team performance-based compensation/individual performance-based compensation; (2) strong id/team performance-based compensation/individual flat wage; (3) strong id/team flat wage/individual performance-based compensation; (4) strong id/team flat wage/individual flat wage; (5) weak id/team performance-based compensation/individual performance-based compensation; (6) weak id/team performance-based compensation/individual flat wage; (7) weak id/team flat wage/individual performance-based compensation; (8) weak id/team flat wage/individual flat wage.
} 
are computed as a participant's allocation of team compensation, plus her individual compensation, less her effort cost. Team and individual compensation is either performance-based or flat, depending on the experimental condition. Like auditor bill rates, solo and team effort cost the same per unit, and total effort becomes increasingly costly with the number of effort units chosen. The dependent measures are participants' solo and team effort choices and output.

Consistent with prior research, I find that performance-based compensation (whether team or individual) and strong team identity lead to better performance. Interactions between team identity and compensation plan indicate that individual performance-based compensation leads to higher solo effort and better performance regardless of team identity, but team performance-based compensation is more effective at motivating team effort when team identity is weak. While the combination of team and individual performance-based compensation results in the highest output, the incremental performance boost is higher from the first performance-based reward strategy, regardless of whether it is team or individual. Offering a combination of individual and team performance-based compensation results in essentially the same performance outcome, regardless of team identity, suggesting that low productivity levels associated with weak team identity can be overcome with joint team and individual performance-based compensation.

This study extends the compensation literature by demonstrating that team and individual performance-based compensation jointly improve performance. However, the incremental output boost from performance-based compensation is higher for the first 
than the second plan, regardless of whether it is team or individual. Additionally, results suggest that team and individual rewards, when offered together, can overcome the lower productivity levels associated with weak team identity.

The remainder of the paper is organized as follows. Section II provides a review of the relevant literature. Section III develops the hypotheses. Section IV describes the research design and task, and section V discusses the results. Section VI concludes. 


\section{LITERATURE REVIEW}

In this section I discuss prior literature which examines teams and performance, specifically the literature on team size, task, and identity. Second, I review prior literature on individual compensation's effect on performance. Finally, I discuss prior literature which examines team compensation's effect on performance.

\section{Teams and Performance}

Team performance has been studied extensively. Prior literature's consensus finds that team size, task, and identity affect performance. With a few exceptions, the consensus is that smaller teams, three to five members, are more effective than larger teams. Much of the research on team size and performance is conducted in education settings. Colbeck et al. (2000) and Hilborn (1994) find that four to five students is the ideal size for college-level group project teams. However, Banios (1991) finds that larger teams, five to eight students, work best for group projects. When cooperative learning is critical, Nastasi and Clements (1991) suggest that two to five member teams are best. Wolfe and Chacko (1983) find that teams of three work best when business games are involved.

Two studies contradict the "smaller is better" team size rule of thumb. Using company data on 72 employee involvement programs, with team sizes ranging from 8 to 40 members, Magjuka and Baldwin (1991) find a positive association between team size and team effectiveness. Their results suggest that fewer teams (with more team members) reduce administration costs leading to a positive relationship between team size and team effectiveness as measured by participants' and their supervisors' 
perceptions of the employee involvement program's ability to improve departmental and firm effectiveness and obtain performance objectives. Haleblian and Finkelstein (1993) examine top management team size and firm performance. They find that larger management teams are positively associated with firm performance for computer industry companies, but not for natural gas distribution industry companies. They attribute this difference to industry environment; the computer industry is turbulent; the natural gas distribution industry is stable. Haleblian and Finkelstein (1993) suggest that larger management teams have the potential to generate more ideas, which benefits the rapidly changing, or turbulent environment, companies more than the stable environment companies. All of the management teams they examine consist of fewer than nine members.

Team work assignments create opportunities to free ride. The Ringlemann effect suggests that as team size increases, people extend less effort (Latane et al. 1979). Ringlemann examined rope pulling and found that individuals on two-person teams pulled at $93 \%$ of their original effort (i.e., when pulling alone). Individuals on teams of three pulled at $85 \%$ of their original effort; individuals on teams of eight pulled at $49 \%$ of their original effort. A reduction in personal effort also occurs with clapping and cheering (Latane et al. 1979). To reduce free riding by improving monitoring ability, Bacon et al. (1999) suggests limiting team size to 4 or fewer members.

If the use of teams leads to free-riding, why do companies and classes use teams? When individual effort toward task completion is additive, and thus no synergies are gained by working in a team, the Ringlemann effect suggests the use of teams is 
inappropriate. However, when the task is interdependent, and synergies are gained from teamwork, then research has found teams of two, three, four, and five members outperform individuals (Bacon et al. 1998; Watson et al. 1991).

Social identity theory suggests that people categorize themselves and others into groups and ultimately make decisions which favor their own groups (Tajfel and Turner 1986). Tajfel and Turner (1986) find that merely being classified as a group member induces own group favoritism, and this favoritism increases with group identity strength. Research finds stronger team identity results in higher contributions to the team and better performance (Wech et al. 1998; De Cremer and van Vugt 1999; De Cremer and van Dijk 2002). Wech et al. (1998) survey 471 United States Air Force and civilian employees and find that team identity can explain performance variance after controlling for task competence.

Using three public goods dilemma experiments, De Cremer and Van Vugt (1999) find that team identity and cooperation are positively related and that this relationship is due to individuals assigning more value to the public good, and not to individuals trusting the cooperative nature of their teammates more, when team identity is high. Also using a public goods dilemma experiment, De Cremer and van Dijk (2002) find that strong team identity results in better cooperation, but only when participants receive no team performance feedback.

Prior literature also finds that teammate familiarity is associated with better performance. Goodman and Leyden (1991) find miners continuously assigned to the same section, job and crew mine more coal per shift than miners on crews with high 
absenteeism. Gruenfeld et al. (1996) also find that familiar teams outperform stranger teams. Familiarity may create group cohesion which is positively associated with team performance (for a review see Cohen and Bailey 1997). Companies often use unfamiliar teams out of convenience, since the variety of skill sets necessary for some team projects are not shared by all employees.

\section{Individual Compensation and Performance}

Individual incentive pay results in better individual performance (e.g., Chow 1983; Sprinkle 2000; Fessler 2003; Irlenbusch and Ruchala 2008). Chow (1983) finds that participants assigned to a pay plan and paid based on a piece rate for a decoding task outperform those paid a fixed rate and those paid for making budget. In a second experiment, participants choose between a fixed and a budget-based compensation plan and those who choose the budget-based plan outperform those who choose the fixed plan. In comparing the performance of those assigned to a fixed payment to those who choose a fixed rate plan, Chow (1983) finds that those who choose a fixed rate plan perform worse, suggesting that poor performing workers self-select into jobs that do not pay for performance.

Fessler (2003) examines individual incentive compensation and finds that task attractiveness and task complexity moderate the positive effect of individual incentives on performance. Given a complex task that participants self-rate as attractive (unattractive), participants paid a fixed-wage (piece-rate) outperform those paid a piecerate (fixed-wage). Fessler's results suggest that incentive compensation works best when the task is both complex and unattractive. 
Sprinkle (2000) finds that individual incentive pay positively affects performance, but only after the task is well understood. He uses a 60 period experiment in which participants" output decisions combine with "states of nature" (i.e., uncontrollable aspects of productivity) to determine profit. During the first 15 periods, Sprinkle (2000) finds no performance difference between those in the incentive pay condition and those in the flat-wage condition. However, after the $15^{\text {th }}$ period incentive payments result in better performance. The results of his study suggest that for tasks where experience matters, individual incentives may result in better performance after a learning period.

Using four person teams, Irlenbusch and Ruchala (2006) examine a combination of team and relative individual performance-based plans and find that only substantial individual performance-based bonuses increase effort. Their team task is additive and their individual performance-based bonus is paid only to the team's highest contributor.

\section{Team Compensation and Performance}

Expectancy theory and agency theory predict a positive association between team incentives and performance (Van Eerde and Thierry 1996; Long 2005). Vroom's expectancy theory predicts that people make choices to maximize their happiness (Vroom 1964). He bases his theory on three beliefs: (1) instrumentality, there is a relationship between an outcome (team performance) and another outcome (team pay); (2) expectancy, the expected probability of good (poor) team performance resulting in more (less) team incentives; and (3) valance, employees attach value to rewards (Vroom 1964; Van Eerde and Thierry 1996). Per agency theory, firms create contracts to reduce 
moral hazard when the interest of principals and agents diverge. Welbourne and Mejia (1995) suggest paying for team performance leads to mutual monitoring among teammates, thus reducing moral hazard.

Cognitive-evaluation theory and distributive justice theory predict a negative association between team incentives and performance (Van Eerde and Thierry 1996; Long 2005). Deci and Ryan's cognitive-evaluation theory suggests that paying for performance is negatively associated with performance in the presence of intrinsic motivation because extrinsic motivators (e.g., monetary incentives) decrease intrinsic motivation, leading to lower performance (Deci and Ryan 1985). Distributive justice theory suggests that people monitor teammates by comparing the ratio of their inputs (such as performance) and outputs (such as rewards) to those of others, and if free-riding by others is detected, they increase their own free-riding to obtain equity (Bartol and Locke 2000).

While theoretical predictions vary, most of the empirical evidence supports a positive relationship between team incentives and performance (e.g., Fisher et al. 2003; Towry 2003; Rankin 2004; Roman 2006). The exceptions include Fredrickson (1992) which finds that worker effort is higher under a relative performance evaluation compensation system than under a profit-sharing system. ${ }^{5}$ He also finds that uncertainty moderates the effect of compensation on performance. In his experiment, participants are assigned to three-person teams. Each participant acts as a manager and his/her task is to make production decisions. The task is not interdependent and does not allow

\footnotetext{
5 "Relative performance evaluation is the process of comparing performances across workers." (Frederickson 1992, p. 647).
} 
synergies to develop among team members. Teams are only used as comparison groups to provide relative performance feedback. Fredrickson finds that as uncertainty about product quality increases, effort increases significantly for the relative performance evaluation condition participants, but not for the profit-sharing condition participants.

Roman (2006) uses aggregate monthly (and limited aggregate weekly) production unit archival data from three production units at one manufacturing plant to examine the association between team incentives and performance. He finds that team incentives are associated with higher productivity and lower product defects. However, confounding events, such as administrative policy changes, also occurred around the time that the plant implemented its incentive plan so causality cannot be inferred from his results.

Towry (2003) finds that the effectiveness of monitoring systems depends on group identity. When group identity is strong (i.e., when teammates know one another) horizontal, or mutual monitoring, systems are more effective than vertical systems. A vertical system exists when participants report teammates' effort to a supervisor in stage two of a game. A horizontal monitoring system exists when participants can punish teammates in period two of the game for performance in period one.

Extending Chow (1983), Fisher et al. (2003) use two person teams and a computerized decoding task to experimentally examine the effect of three compensation schemes (group piece-rate, group budget-fixed, and group budget-linear) and three budget levels (low, medium, and high) on group performance. Participants in the budget-fixed treatment group receive a fixed amount of compensation once they meet 
budget; participants in the budget linear treatment group receive a fixed amount of compensation once they meet budget, plus a piece rate for every unit above budget. In Fisher et al. (2003) the group budget-linear with a medium budget level condition outperformed all other treatment conditions. Fisher et al. (2003) suggest future research increase team size, since team size has been shown to effect cooperation, and use an interdependent task, since the synergistic nature of performance computations for interdependent tasks may also affect teammate behavior.

Using two-person teams in a production setting, Rankin (2004) compares worker performance under two performance-based compensation systems (team and individual), two coordination environments (teams maintain the same two members for all 15-plus periods - high and teams switch members each period - low) and two information environments (team effort monitoring only and both team and solo effort monitoring). When workers cannot coordinate their activities (i.e., when participants play one shot games), Rankin finds that team-based incentives lead to better performance. However, when workers can coordinate their activities (i.e., when participants play repeated games with the same teammate), he finds that individual incentives lead to better performance. Rankin suggests that under individual incentives, participants' behavior is similar to the "fully cooperative equilibrium," while under team-based incentives participants' behavior is similar to the "partial cooperative equilibrium," meaning teammates cooperate but also free ride. Additionally, Rankin finds that when coordination is high (i.e., when team membership is constant) the performance difference between low and high information environments is greater under team-based than individual-based 
incentives, suggesting when team incentives are used workers need more information about their teammates' behavior to induce cooperation. 


\section{BACKGROUND AND HYPOTHESIS DEVELOPMENT}

The focus of this study is the possible interaction effects on solo and team effort and performance of three manipulated variables - team identity, team compensation plan, and individual compensation plan. My hypotheses address the predicted interactions.

\section{Team Identity}

Familiarity and team cohesiveness (i.e., team identity) are contextual factors that have been shown to affect performance and that may influence the effectiveness of team compensation. Thus, I investigate whether team identity affects compensation scheme effectiveness.

Social identity theory suggests that people categorize themselves and others (i.e. student, professor, Texan, liberal, conservative) and make decisions and judgments that favor their own groups; this favoritism increases with team identity strength (Tajfel and Turner 1986). ${ }^{6}$ Additionally, research finds that stronger team identification leads to better performance and higher contributions to the team (Wech et al. 1998; De Cremer and van Vugt 1999; De Cremer and van Dijk 2002). The literature on team identity also finds that familiarity among team members - not necessarily the same phenomenon as team identity - increases performance and information sharing (Goodman and Leyden 1991; Gruenfeld et al. 1996). ${ }^{7}$

In the accounting literature, King (2002) finds that strong auditor team identity reduces auditors' tendencies to identify with clients, which reduces audit report bias (i.e.,

\footnotetext{
${ }^{6}$ Tajfel and Turner (1986) find that merely being classified as a group member can induce own group favoritism.

${ }^{7}$ In Goodman and Leyden (1991) coal miner teams with consistent membership are considered more familiar than teams with membership changes due to absenteeism. In Gruenfeld et al. (1996) teams whose teammates have had prior (no prior) interactions are labeled familiar (stranger).
} 
improves performance), and Towry (2003) finds that when team identity is strong, horizontal monitoring systems (i.e., mutual monitoring) are more effective than vertical monitoring systems. Towry's results suggest that teams with strong identity are more successful when they manage themselves. Both results suggest that teams with strong identity will take actions to improve team performance. Consistent with this literature, I expect strong team identity to lead to more team effort and better performance.

\section{Performance-based Compensation}

A large body of evidence shows that incentive pay improves performance (e.g., Chow 1983; Sprinkle 2000; Fessler 2003), at least for individuals. Chow (1983) finds that participants paid based on a piece rate for a decoding task outperform both those paid a fixed rate (flat wage) and those paid based on achieving a budgeted output level, although whether the pay plan was chosen by the worker or assigned also affects performance. Fessler (2003) finds that performance-based compensation improves performance for inherently unattractive tasks, but not for inherently attractive tasks, and Sprinkle (2000) finds individual performance-based compensation improves performance after a learning period. Consistent with this literature, I expect individual performance-based compensation to lead to more individual effort and better performance.

Team performance-based compensation should motivate mutual monitoring to reduce free riding and improve performance (Welbourne and Mejia 1995). However, distributive justice theory suggests that people monitor by comparing the ratio of their inputs (such as performance) and outputs (such as rewards) to those of others, and if 
free-riding by others is detected, they increase their own free-riding to obtain equity (Bartol and Locke 2000). Thus, there is room for different predictions about the influence of team performance-based compensation on effort and performance.

Agency theory suggests a decrease in free-riding due to mutual monitoring, but distributive justice theory suggests a possible increase in free-riding that depends on how much free riding is detected early in a project. However, few studies examine the effect of team performance-based compensation as a substitute for monitoring and those that do find improved performance (Fisher et al. 2003; Rankin 2004; Roman 2006). For example, using archival data, Roman (2006) finds that team incentives are associated with higher productivity and lower product defects, but he cannot conclude with certainty that the association between team incentives and performance is causal because confounding events, such as changes in administrative policies, also occurred around the time the plant implemented the incentives. My laboratory experiment allows me to examine the effects of performance-based compensation while holding other context variables constant, which allows me to make casual inferences about the effect of team incentives on performance.

Fisher et al. (2003) use two member teams and a computerized decoding task to examine the effect of three types of performance-based compensation systems on team performance. The three systems are team piece-rate, team fixed-budget, and team linearbudget compensation schemes. The budget-related conditions include low, medium, and high budget targets. Fisher et al. (2003) find that the team linear-budget system, with a 
medium budget target, outperforms other performance-based compensation systems. ${ }^{8}$ I extend Fisher et al. (2003) by testing the joint effect of a team performance-based compensation system, similar to Fisher et al.'s team piece-rate compensation system, and an individual performance-based compensation.

Rankin (2004) explores the effects of coordination environment, information environment, and compensation system on performance and defines compensation system as the method for paying participants, coordination environment as participants' ability to build reputation, and information environment as participants' ability to monitor teammates. He operationalizes compensation system levels as either team output (performance-based) or individual output (performance-based), coordination environment levels as high (teams maintain the same two members for all 15-plus periods) or low (teams switch members each period), and information environment as team monitoring only (teammates monitor team effort only) or both team and solo monitoring (teammates monitor both team and solo effort).

Rankin (2004) finds that team incentives result in better performance when team membership is not consistent (low coordination), regardless of monitoring ability. However, when teams are consistent (high coordination), monitoring ability matters. When coordination ability and monitoring ability are both high, a performance-based compensation system is not needed. However, if coordination ability is high, but monitoring ability is low, individual performance-based incentives generate higher output than team performance-based incentives.

\footnotetext{
${ }^{8}$ Participants in Fisher et al.'s (2003) linear-budget treatment group receive a fixed amount of compensation once they meet budget, and a piece-rate for every unit they decode above budget.
} 
In summary, Rankin (2004) finds that participants cooperate more when offered individual incentives. He attributes this to an increased need to monitor one another under team incentives. When team incentives are offered, he finds that teammates cooperate, but they also free-ride. I investigate the joint effect of individual and team performance-based compensation to determine whether the combination induces cooperation while reducing free-riding and I predict that the combined compensation schemes will work together to improve both effort and performance.

Although prior literature shows a positive association between team identity and performance (Goodman and Leyden 1991; Gruenfeld et al. 1996; Cohen and Bailey 1997; Wech et al. 1998; De Cremer and van Vugt 1999; De Cremer and van Dijk 2002; King 2002; Towry 2003), no prior work investigates whether and how team identity influences the effectiveness of either individual or team performance-based compensation. I expect participants in weak team identity conditions to internalize team membership less, and therefore to respond more to individual performance-based compensation than participants in strong team identity conditions by supplying more solo effort. Performance is measured as individual output, which increases with both solo and team effort and is optimized when all teammates exert both effort types. ${ }^{9}$ This leads to my first hypothesis, which predicts that individual performance-based compensation is more influential in weak than strong identity conditions. See Figure 1.

H1: Individual performance-based compensation will produce a larger increase in individual performance (and effort) in weak than strong identity conditions.

\footnotetext{
${ }^{9}$ Optimal solo output of 103 is achieved when each teammate chooses 30 units of team effort and 20 units of solo effort.
} 
FIGURE 1

Diagram of Hypothesis 1

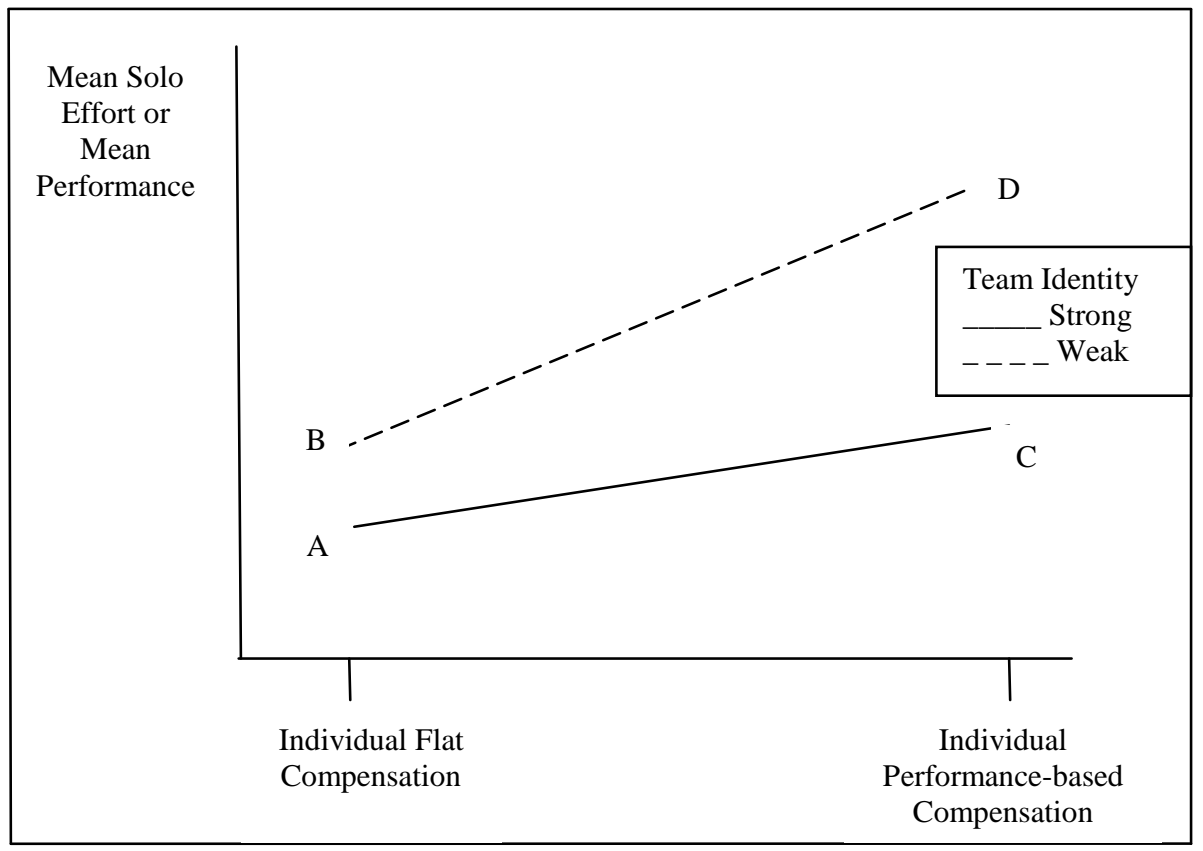

Figure 1 shows the predicted effect on performance (and effort) of flat versus performance-based individual compensation. Hypothesis 1 predicts that the slope of the weak team identity line is positive and steeper than the slope of the strong team identity line, or equivalently, that the difference between points $\mathrm{D}$ and $\mathrm{B}$ is larger than the difference between points $\mathrm{C}$ and $\mathrm{A}$. Thus, hypothesis 1 predicts an interaction between individual compensation scheme and team identity. 
I expect that participants in strong team identity conditions internalize team membership more than participants in weak identity conditions and, consequently either (a) respond more to team performance-based compensation than participants in weak team identity conditions, or (b) because they start at an elevated performance level due to strong team identity, respond less to team performance-based compensation than participants in weak identity conditions. As a result, I expect strong team identity participants to either (a) supply more team effort leading to better performance or (b) supply similar effort leading to comparable performance. This leads to two competing hypotheses, one predicting team performance-based compensation is more influential in strong than weak identity conditions (H2a), the second predicting team performancebased compensation is less influential in strong than weak identity conditions (H2b). See Figures 2a and 2b.

H2a: Team performance-based compensation will produce a larger increase in individual performance (and effort) in strong than weak identity conditions.

$\mathrm{H} 2 \mathrm{~b}$ : Team performance-based compensation will produce a smaller increase in individual performance (and effort) in strong than weak identity conditions. 
FIGURE 2a

\section{Diagram of Hypothesis 2a}

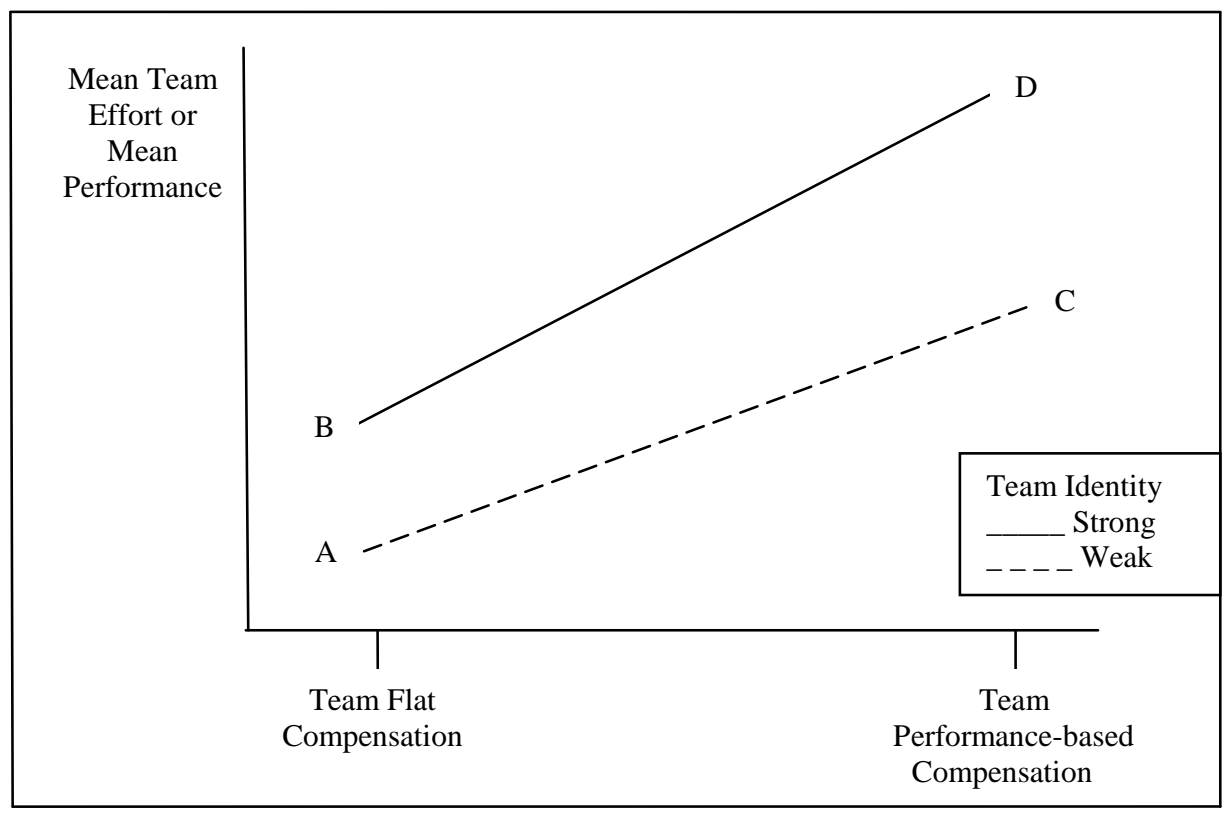

Figure 2a shows the predicted effect on performance (and effort) of flat versus performance-based team compensation. Hypothesis $2 \mathrm{a}$ predicts that the slope of the strong team identity line is positive and steeper than the slope of the weak team identity line, or equivalently that the difference between points $\mathrm{D}$ and $\mathrm{B}$ is larger than the difference between points $\mathrm{C}$ and $\mathrm{A}$. Thus, hypothesis $2 \mathrm{a}$ predicts an interaction between team compensation scheme and team identity. 
FIGURE 2b

Diagram of Hypothesis $2 \mathrm{~b}$

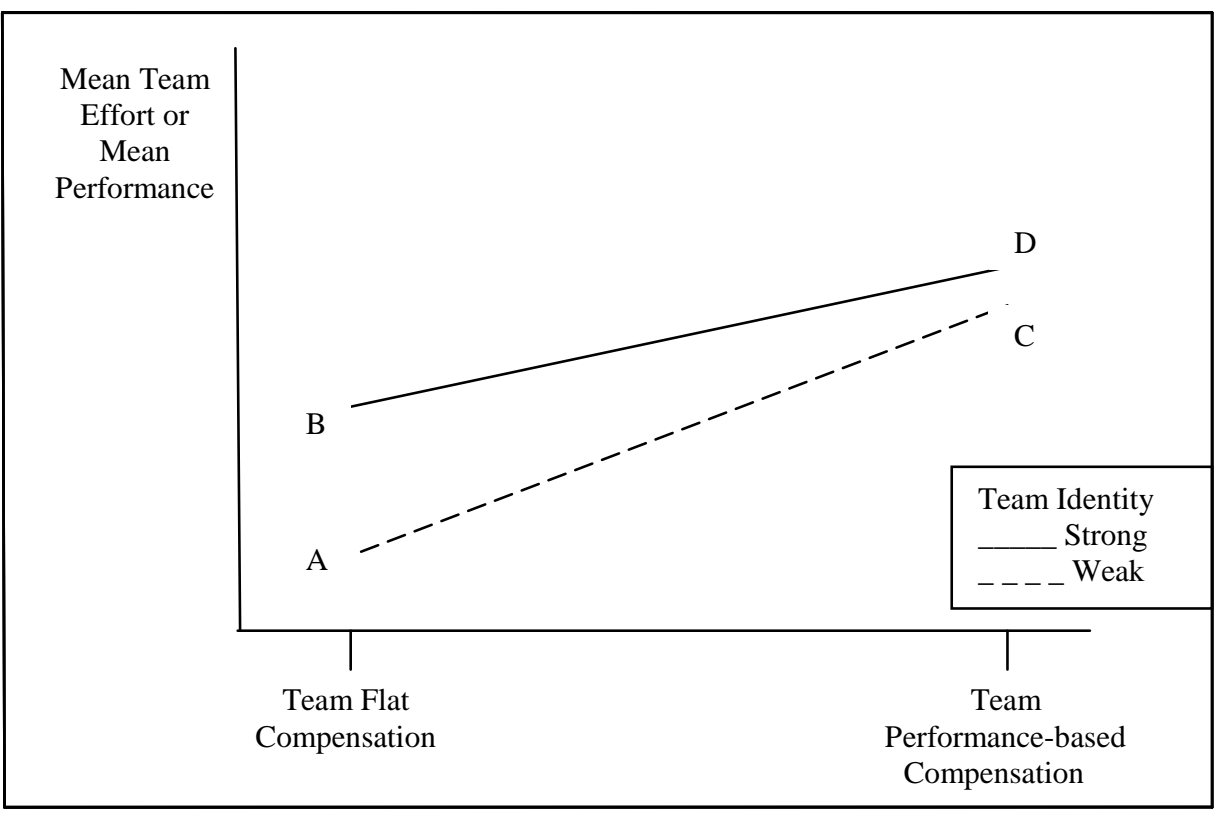

Figure $2 b$ shows the predicted effect on performance (and effort) of flat versus performance-based team compensation. Hypothesis $2 \mathrm{~b}$ predicts that the slope of the strong team identity line is positive and less steep than the slope of the weak team identity line, or equivalently that the difference between points $\mathrm{D}$ and $\mathrm{B}$ is smaller than the difference between points $\mathrm{C}$ and $\mathrm{A}$. Thus, hypothesis $2 \mathrm{~b}$ predicts an interaction between team compensation scheme and team identity. 
Rankin (2004) finds that offering team performance-based compensation alone leads to cooperation but also free-riding when monitoring ability is low. I expect that team incentives encourage cooperative effort and individual incentives encourage solo effort and, therefore, I expect team and individual performance-based compensation to work together to encourage cooperation and reduce free-riding, improving both effort and performance. While I expect the combined compensation schemes to produce the highest output, I also expect that the incremental effect of adding the additional compensation scheme is sub-additive since the compensation schemes are partial substitutes. Thus, I expect that the biggest incremental performance gain occurs when one performance-based scheme is combined with a flat payment plan. This leads to my third hypothesis. See Figure 3.

H3: Team performance-based compensation will show a larger positive influence on individual performance (and effort) when individual compensation is flat. 
FIGURE 3

Diagram of Hypothesis 3

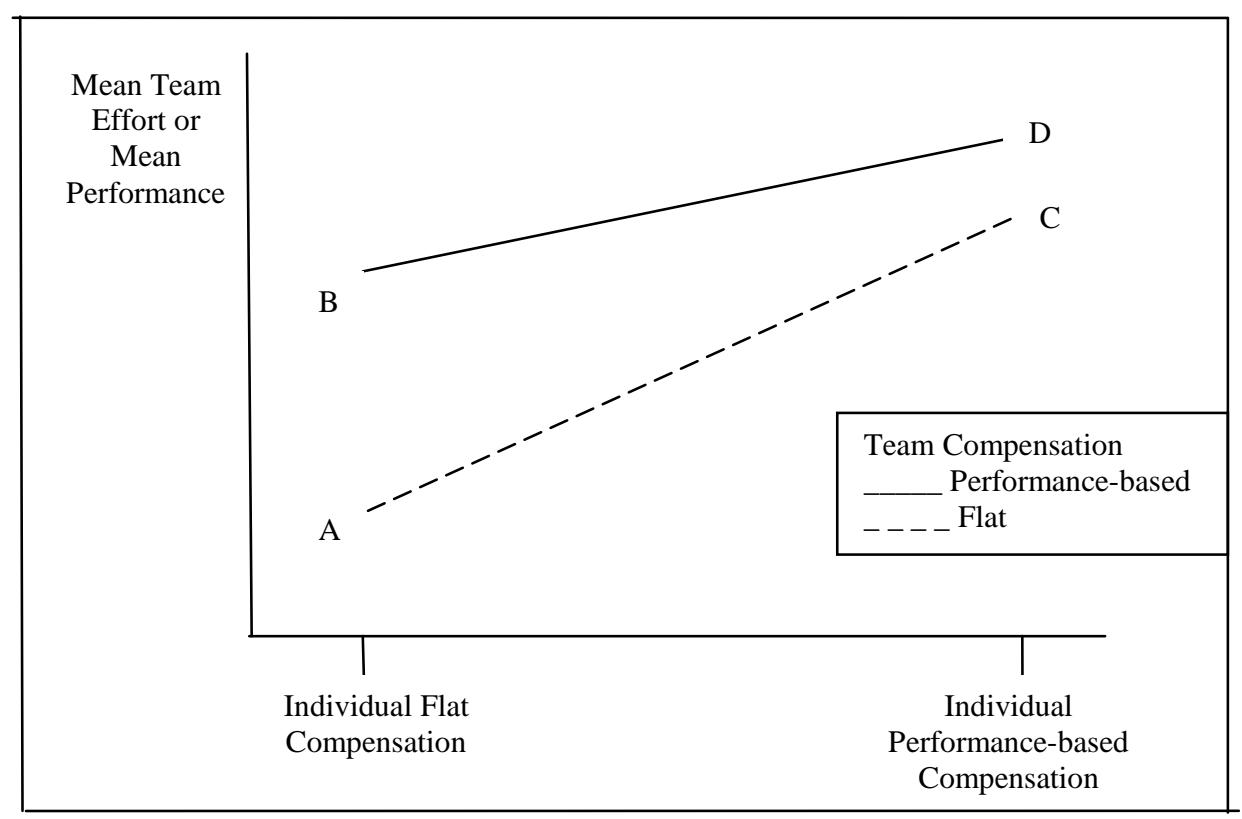

Figure 3 shows the predicted effect on performance (and effort) of flat versus performance-based individual compensation. Hypothesis 3 predicts that the slope of the team flat line is positive and steeper than the slope of the team performancebased line, or equivalently that the difference between points $\mathrm{C}$ and $\mathrm{A}$ is larger than the difference between points D and B. Thus, hypothesis 3 predicts an interaction between team compensation scheme and individual compensation scheme. 
I expect that team and individual performance-based compensation work together to reduce free-riding and improve effort and performance. Since the team identification literature predicts a positive association between strong team identity and performance (Goodman and Leyden 1991; Gruenfeld et al. 1996; Wech et al. 1998; De Cremer and van Vugt 1999; De Cremer and van Dijk 2002; King 2002; Towry 2003), I predict that individual and team performance-based compensation will jointly improve effort and performance more in the strong than in the weak identity conditions resulting in a significant three-way interaction between the two compensation schemes and team identity. This leads to my next set of hypotheses (See Figure 4).

H4a: In the weak team identity condition, team performance-based compensation improves performance (and team effort) significantly when individual compensation is flat, but adds nothing when individual compensation is performance-based.

H4b: In the strong team identity condition, team performance-based compensation improves performance (and team effort) by the same amount whether individual compensation is flat or performance-based. 
FIGURE 4

Diagram of Hypothesis 4

\section{Panel A: When Team Identity is Weak}

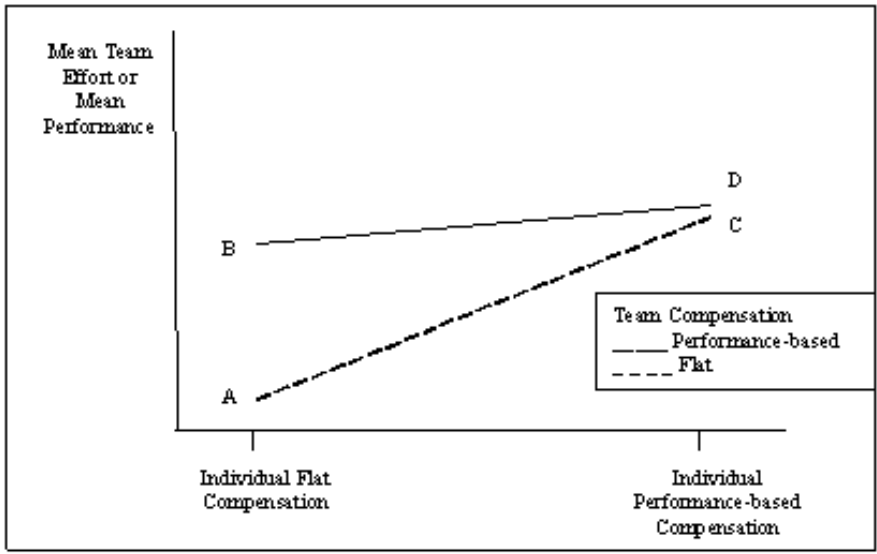

Panel A shows the predicted effect on performance (and team effort) of team and individual performance-based compensation when team identity is weak. Hypothesis 4a predicts that the slope of the flat team line is positive and steeper than the slope of the performance-based team line, or equivalently that the difference between points $\mathrm{C}$ and $\mathrm{A}$ is larger than the difference between points $\mathrm{D}$ and $\mathrm{B}$. Taken together, $\mathrm{H} 4 \mathrm{a}$ and $\mathrm{H} 4 \mathrm{~b}$ predict a three-way interaction among individual compensation, team compensation, and team identity.

\section{Panel B: When Team Identity is Strong}

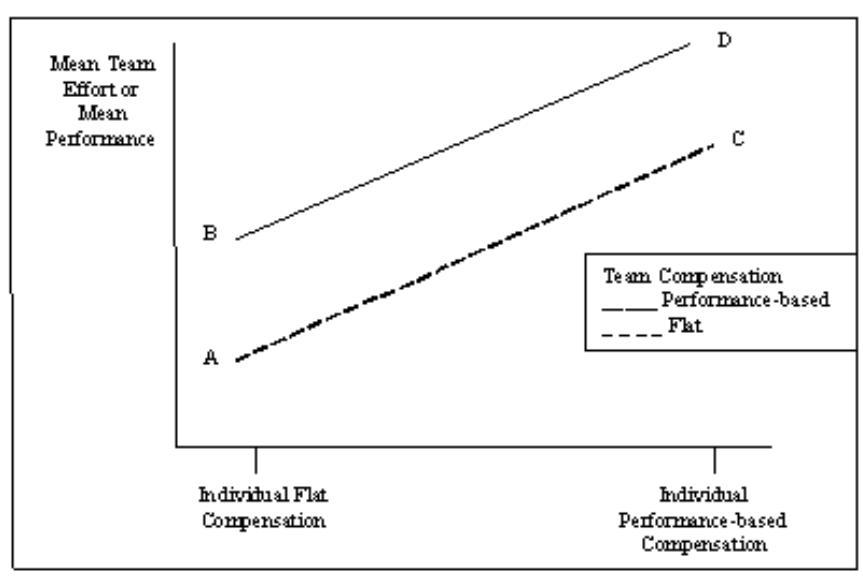

Panel B shows the predicted effect on performance (and team effort) of team and individual performance-based compensation when team identity is strong. Hypothesis $4 \mathrm{~b}$ predicts that the slopes of the flat and performance-based compensation lines are positive and do not differ significantly, or equivalently that the difference between points $\mathrm{C}$ and $\mathrm{A}$ is similar to the difference between points $\mathrm{D}$ and $\mathrm{B}$. Taken together, $\mathrm{H} 4 \mathrm{a}$ and $\mathrm{H} 4 \mathrm{~b}$ predict a three-way interaction among individual compensation, team compensation, and team identity. 


\section{RESEARCH METHOD}

Participants are 96 undergraduate students from a large southwestern university. My experimental task does not require expert knowledge or skills, so students are appropriate participants (Peecher and Solomon 2001). All participants are currently enrolled in an accounting class and earn extra course credit ranging from $0.5-2.5 \%$ on their final grade for participating. ${ }^{10}$ Additionally, two lottery winners in each session receive $\$ 40$ making the average monetary payout per participant $\$ 5.00 .^{11}$ Twelve participants are randomly assigned to each of eight conditions $(8 \times 12=96) .^{12}$

Experiment sessions last approximately 90 minutes and take place outside of regular class time in the computer lab. Table 1 shows demographic data.

\section{Design}

I manipulate team and individual compensation plans, and team identity in a $2 \times$ $2 \times 2$ between-subjects design. The task is completed in 18 periods resulting in repeated within-subject responses.

\footnotetext{
${ }^{10}$ Participation points differed by professor. Participants knew only their own extra credit amount.

${ }^{11}$ Experiment sessions were run with 16 participants per session $(\$ 40+\$ 40=\$ 80 / 16$ participants $=$ average payout of $\$ 5$ per participant).

${ }^{12}$ Two outlier individuals and their teammates were dropped from the data. To obtain a balanced design one group was randomly chosen and dropped from each additional condition. This results in three groups or 12 participants per condition.
} 


\section{TABLE 1 \\ Demographic Data}

\begin{tabular}{|c|c|c|c|}
\hline & Number & & Percent \\
\hline Total Participants & 96 & & 100.0 \\
\hline \multicolumn{4}{|l|}{ Participants' year in school: ${ }^{1}$} \\
\hline Freshman & 4 & & 4.2 \\
\hline Sophomore & 7 & & 7.3 \\
\hline Junior & 71 & & 74.0 \\
\hline Senior & 13 & & 13.5 \\
\hline No Response & 1 & & 1.0 \\
\hline \multicolumn{4}{|l|}{ Participants' gender: ${ }^{2}$} \\
\hline Male & 47 & & 49.0 \\
\hline Female & 48 & & 50.0 \\
\hline \multirow[t]{2}{*}{ No Response } & 1 & & 1.0 \\
\hline & Mean & Median & (S.D.) \\
\hline Average prior courses with team work: ${ }^{3}$ & 6.46 & 5 & $(6.663)$ \\
\hline Average self-assessed risk: ${ }^{4}$ & 3.687 & 4 & $(3.132)$ \\
\hline
\end{tabular}

${ }^{1}$ Data come from 95 responses to the following exit survey question: "Please indicate your year in school (freshman, sophomore, etc.)." One participant did not respond to this question. Based on ANOVA testing, response means are not significantly different across treatment conditions $(F=1.006, p=0.433)$.

${ }^{2}$ Data come from 95 responses to this exit survey question: "Please indicate whether you are male or female (Check one)." One participant did not respond to this question. Based on ANOVA testing, response means are not significantly different across treatment conditions $(\mathrm{F}=1.879, \mathrm{p}=0.083)$.

${ }^{3}$ Data come from 95 responses to this exit survey question: "Please indicate how many courses you have taken previously which included group work (include courses you are taking this semester)." One participant did not respond to this question. Based on ANOVA testing, response means are not significantly different across treatment conditions $(\mathrm{F}=0.872, \mathrm{p}=0.532)$.

${ }^{4}$ Data come from 94 responses to this exit survey question: "If given the choice between the following, which would you choose (circle one per line): $\$ 400$ or $40 \%$ chance for $\$ 1,000, \ldots, \$ 8,000$ or $80 \%$ chance for $\$ 10,000$." Two participants did not respond to this question. Participants' risk choices (their second options) are summed and that summary number is used for analysis. The summary values ranges from 0 14, with 0 (14) indicating a person is risk neutral (seeking). Based on ANOVA testing, at least one response mean is different across treatment conditions $(F=2.501, \mathrm{p}=0.022)$. Post-hoc analysis identified the Team Flat/Individual Flat/Weak identity condition's mean is less than that of the Team Flat/Individual Performance-Based/Strong identity condition. 
Manipulated variables. Team and individual compensation are manipulated as fixed compensation (flat team wage or flat individual wage) or compensation computed as a function of either team or individual output (performance-based team compensation or performance-based individual compensation). Following Towry (2003), I use team member introductions, unique paper colors, and team competitions to create strong group identity (See also Eckel and Grossman 2005; Shelley and Zhao 2007). I use team member anonymity, white paper, and individual competitions to create weak group identity. The top team earns (the top four individuals earn) carnival prizes for team (individual) puzzle and quiz competitions.

Dependent measures. Responses are the two effort choices. Dependent variables in statistical analyses are effort choices and individual output (i.e., performance). ${ }^{13} \mathrm{~A}$ participant's solo output is computed using his/her solo effort and his/her teammates' team effort. Team output is the sum of all teammates' solo outputs. Optimal solo output of 103 is achieved when each teammate expends team effort of 30 and solo effort of $20 .^{14}$

\footnotetext{
${ }^{13}$ Since team output is merely the sum of teammates' solo outputs, it is not analyzed.

${ }^{14}$ The computation of solo output follows Rankin (2004) modified for four people. The optimal effort choices and optimal solo output would change if the formula changed.
} 
Expressions (1) through (8) below show how individual and team output and compensation are computed for the truck loading task. Teams are assumed to have four identical agents, $i, j, k$, and $l$ (Rankin 2004). Agent $i$ 's solo output per period, $M_{i}$, is a function of both agent $i$ 's effort, $e_{i i}$, toward his individual output and his teammates' efforts, $e_{j i}, e_{k i}, e_{l i}$, toward team output. ${ }^{15}$

$$
M_{i}=e_{i i}+3\left(e_{i i}^{0.25} e_{j i}^{0.25} e_{k i}^{0.25} e_{l i}^{0.25}\right)
$$

Expression (1) adjusts Rankin (2004) for the increase in team size by changing the effort exponents from .5 to .25 . Rankin used exponents of 0.5 because he had two-person teams $(1 \div 2=0.5)$. I use exponents of 0.25 because I have four-person teams $(1 \div 4=$ 0.25). Rankin included the multiplier of 3 to create greater disparity between his optimal solo and team effort choices, purposefully creating an environment in which similar effort units for both effort types was not optimal.

Total team output per period, $T$ in expression (2), is the sum of all agents' solo outputs.

$$
T=M_{i}+M_{j}+M_{k}+M_{l}
$$

The cost of effort $\left(\mathrm{CE}_{\mathrm{i}}\right)$ for agent $i$, expression (3), is the same as Rankin's (2004) cost of effort function.

$$
C E_{i}=\left(e_{i i}+e_{i j}\right)^{2} / 50
$$

Effort becomes more costly per unit as it increases and total (solo and team) effort choices over 50 units are not rational because the cost exceeds the benefit. Solo and

\footnotetext{
${ }^{15}$ Solo and team output functions are identical to those used by Rankin (2004) except that I do not incorporate a random variable to mask teammate effort choices because my team size masks teammate effort choices.
} 
team effort costs are equal and therefore, based on effort costs alone, agents should be indifferent between solo and team effort. The cost of effort (expression (3)) is subtracted from total compensation to arrive at net compensation.

Total compensation for agent $i, C_{i}$, is computed as the agent's proportionate share of team compensation plus his/her individual compensation. Flat compensation is, of course, not based on output. Team performance-based compensation is a function of team output; individual performance-based compensation is structured as a bonus and earned when solo output equals or exceeds the average (across all individuals in the session and all periods to date) solo output $\left(B_{i}\right)$. Total compensation computations are shown below by experimental condition:

(A) Flat Team/Flat Individual Compensation

$$
C_{i}=100+50
$$

(B) Flat Team/Performance-based Individual Compensation

where:

$$
C_{i}=100+\left[100 \times 50 \% \times B_{i}\right]
$$

$B_{i}$ equals 1 when individual $i$ 's output equals or exceeds the average output of all other agents to date, and 0 otherwise. $B_{i}$ triggers $i$ 's bonus.

(C) Performance-based Team/Flat Individual Compensation

where:

$$
C_{i}=\left[1 / 4\left(M_{i}+M_{j}+M_{k}+M_{l}\right)\right]+50,
$$

$$
M_{n}(n=i, j, k, l) \text { is expression (1). }
$$


(D) Performance-based Team/Performance-based Individual Compensation where:

$$
C_{i}=\left[1 / 4\left(M_{i}+M_{j}+M_{k}+M_{l}\right)\right]+\left[\left(1 / 4\left(M_{i}+M_{j}+M_{k}+M_{l}\right)\right) \times 50 \% \times B_{i}\right],
$$

$B_{i}$ equals 1 when individual $i$ 's output equals or exceeds the average output of all other agents to date, and 0 otherwise, $B_{i}$ triggers $i$ 's bonus. $M_{n}(n=i, j, k, l)$ is expression (1).

An individual's net compensation, $\Pi$, is computed by subtracting cost of effort from total compensation:

where

$$
\Pi\left(C_{i}, C E_{i}\right)=C_{i}-C E_{i}
$$

$C_{i}$ is expression (4), (5), (6), or (7) depending on the experimental condition, and $C E_{i}$ is expression (3).

Task. I use the truck loading task from Alchian and Demsetz (1972) and Rankin (2004), in which two people working together load one truck faster than two people working in parallel load one truck. The truck loading task has evolved, resulting in recent experiments not using the truck loading context within the materials. My experiment is no different; participants receive no references to truck loading during my experiment. Rankin (2004) modified the task by constructing a two-person/two-truck task in which each person makes two effort choices: (1) effort toward loading his/her own truck, and (2) effort toward helping his/her teammate load his/her truck. I further modify the truck loading task by creating a four person/four truck production environment in which participants make two effort choices: (1) effort toward loading his/her own truck (solo effort), and (2) effort toward helping his/her teammates load 
their trucks (team effort). ${ }^{16}$ Participants choose their solo and team effort levels by selecting two integers from 0 to 100 . Solo effort represents effort toward solo output and team effort represents effort toward team output. Using a computer program participants make effort choices for each of 21 periods (see Appendix A for screen prints of the computer game created using z-Tree; Fischbacher 2007). The first three periods are practice or pre-production periods and output from these periods is not included in compensation calculations. Total net compensation from the remaining 18 production periods is converted into lottery tickets. ${ }^{17}$

Procedure. Participants arrive at the computer lab, sit in randomly assigned seats, and read an overview of the experiment. See Appendix B. Next participants sign their consent forms and complete the first of two identity-manipulation tasks. Next the experiment administrator publicly reads the instructions, administers a quiz over the instructions, and awards quiz prizes. ${ }^{18}$ The instructions and quiz are available in Appendices C and D, respectively. Once identity-manipulation prizes are distributed, participants begin the experimental task of making a series of two effort choices (solo and team effort) in each of 21 periods. Next, participants answer manipulation check and demographic questions on the exit survey, see Appendix E. Finally, participants are paid, thanked and dismissed.

\footnotetext{
${ }^{16}$ Participants' team effort helps all other teammates load their trucks.

${ }^{17}$ To avoid end game strategies participants are not told the total number of production periods.

${ }^{18}$ I run only one condition per session.
} 


\section{RESULTS}

\section{Manipulation Checks}

The exit survey asks participants to respond to a series of 26 questions that include manipulation checks for individual compensation, team compensation, and team identity manipulations. The individual compensation manipulation check question reads "My qualifying for solo compensation depended on my solo output (indicate the degree to which you agree/disagree [on an 11-point scale]).” Responses were significantly different across individual compensation conditions, indicating that participants understood their own individual compensation condition, individual flat or individual performance-based compensation $(\mathrm{t}=8.716, \mathrm{p}=0.000)$. Thus, I conclude that the individual compensation manipulation was effective. Results from the team compensation manipulation check question, which read "My team compensation depended on my team's output (indicate the degree to which you agree/disagree [on an 11-point scale])," indicate that participants also understood their own team compensation condition, flat or team performance-based compensation $(t=11.648, p=0.000)$. Thus, $I$ conclude that the team compensation manipulation was effective.

Nearly all participants $(99.0 \%)$ knew whether their teammates were or were not identified to them ("I could point to the people on my team (circle one): True False"). ${ }^{19}$ Participants in the strong identity condition felt closer to their teammates than

\footnotetext{
${ }^{19}$ The percentage of participants responding correctly (based on their condition) did not vary statistically among conditions.
} 
participants in the weak identity condition $(\mathrm{t}=6.805, \mathrm{p}=0.000)$, indicating that the team identity manipulation was effective. ${ }^{20}$

Exit survey results also indicate that participants understood the impact of their

effort choices on output and found neither the experiment scoring nor the computer

portion of the experiment too complicated. ${ }^{21,22}$ On average, participants felt well

compensated for their time, confident about their effort choices, and tried to earn lottery

tickets. $^{23}$

${ }^{20}$ I use an 11-point five-item identity scale adapted from Shelley and Zhao (2007). Using factor analysis I create one measure of team identity. Reliability is confirmed with a Chronbach's alpha of 0.702 .

${ }^{21}$ Responses to six exit survey questions (two multiple choice questions and four Likert scale response questions) support that participants understand the impact their effort choices have on output. The two multiple choice questions (a) "My solo output was affected by..." and (b) "My team output was affected by...." are answered correctly by $96 \%$ and $91 \%$ of the participants respectively. However, the team output question (b) is answered correctly by weak identity condition participants $98 \%$ of the time and strong identity participants $83 \%$ of the time. Participant mean responses to four additional questions which asked participants to "indicate the degree to which you agree/disagree [on an 11-point scale, with one labeled 'strongly disagree' and 11 labeled 'strongly agree']" are all higher statistically than the midpoint response of 6. The questions were as follows: (a) "I understood the impact of my effort choices on my solo output" (mean $=7.36, \mathrm{sd}=2.735)$, (b) "I understood the impact of my effort choices on my team output" $($ mean $=6.63, \mathrm{sd}=2.784)$, (c) "I understood the impact of my teammates' effort choices on my solo output" (mean $=6.8146, \mathrm{sd}=2.872)$, and $(\mathrm{d})$ "I understood the impact of my teammates' effort choices on my team output" (mean $=6.87, \mathrm{sd}=2.70)$. Participant responses do not vary statistically across conditions with the exception of the strong identity condition. Their mean responses are neither higher nor lower than the midpoint of 6, which is labeled "Agree" on the Likert scale.

${ }^{22}$ The experiment scoring question reads as follows: "The scoring used in this experiment was too complicated (indicate the degree to which you agree/disagree [on an 11-point scale, with one labeled 'strongly disagree' and 11 labeled 'strongly agree'])" (mean $=5.31$, sd $=2.788)$. Participants mean response is statistically lower than the midpoint response option of $6(t=2.416, p=0.018)$ with the exception of the team performance-based compensation condition (mean $=5.98, \mathrm{sd}=2.638)$ which is not statistically different from the midpoint of $6(t=0.055, \mathrm{p}=0.957)$. The computer complexity question reads as follows: "The computer portion of this experiment was easy to understand (indicate the degree to which you agree/disagree [on an 11-point scale, with one labeled 'strongly disagree' and 11 labeled 'strongly agree'])" ( mean $=8.05$, sd $=2.641)$. Participants mean response is statistically above the midpoint response option of $6(t=7.612, p=0.000)$. Participant responses do not vary statistically between conditions.

${ }^{23}$ The compensation question reads as follows: "I felt well compensated for my time (indicate the degree to which you agree/disagree [on an 11-point scale, with one labeled 'strongly disagree' and 11 labeled 'strongly agree"])" ( mean $=6.60, \mathrm{sd}=2.540)$. Participants mean response is statistically higher than the midpoint response option of $6(\mathrm{t}=2.311, \mathrm{p}=0.023)$. The confidence question reads as follows: "I was confident about my effort choices (indicate the degree to which you agree/disagree [on an 11-point scale, with one labeled 'strongly disagree' and 11 labeled 'strongly agree'])" ( mean $=6.90, \mathrm{sd}=2.594)$. Participants mean response is statistically higher than the midpoint response option of $6(t=3.387, p=$ 


\section{Descriptive Results}

Table 2 (Panels A, B, and C) provides descriptive statistics for participants' average output, average solo effort, and average team effort per period respectively. Regardless of team identity, the greatest output results from the combination of team and individual performance-based compensation (Table 2, Panel A). However, participants' effort is not always highest when both performance-based compensation schemes are in use. $^{24}$ When team identity is weak, the highest solo effort stems from a combination of team and individual performance-based compensation, but when team identity is strong, the highest solo effort results from individual performance-based compensation alone (Table 2, Panel B). The highest team effort arises when both team and individual performance-based compensation are offered, when team identity is strong (Table 2, Panel C). However, when team identity is weak, team effort does not improve when individual performance-based compensation is added to team incentives (Table 2, Panel C). Participants' effort and output varies more when team identity is strong (i.e., higher standard deviation).

0.001). The attempt to earn lottery tickets question reads as follows: "I attempted to maximize my points / lottery tickets (indicate the degree to which you agree/disagree [on an 11-point scale, with one labeled 'strongly disagree' and 11 labeled 'strongly agree'])" (mean $=9.74, \mathrm{sd}=1.808)$. Participants mean response is statistically higher than the midpoint response option of $6(t=20.263, p=0.000)$. For these three questions, participant responses do not vary statistically between conditions.

${ }^{24}$ Output is created from a participant's solo effort and his teammates' team effort choices, and effort levels closest to optimal result in the best performance. 
TABLE 2

Descriptive Statistics by Condition

Panel A: Output ${ }^{\text {a }}$

Mean $^{\mathrm{b}}$

(Standard Deviation)

Sample Size

Performance-based

\begin{tabular}{cc}
\multicolumn{2}{c}{ Team Identity - Weak } \\
Individual Compensation
\end{tabular}

Team Compensation

Flat

27.3223

68.1815

(20.8722)

(22.0650)

$\mathrm{n}=12$

$\mathrm{n}=12$

Performance-based

77.2052

81.8053

(27.6363)

(22.1583)

$\mathrm{n}=12$

$\mathrm{n}=12$

${ }^{a}$ Table 2, Panel A represents 96 student participants individual output in a computerized experimental game where I manipulate Team Compensation (flat, performance-based), Individual Compensation (flat, performance-based), and Team Identity (weak, strong) between subjects.

${ }^{b}$ Mean is the mean of between subjects mean of the 96 participants' 18 within subjects means by condition. For example, Participant A's total participant output is earned over 18 periods, therefore participant A's mean output is his/her total output divided by 18. Participant A's mean output is summed with the mean outputs of the other 11 participants in his/her condition and then divided by 12 (the total number of participants per condition) to arrive at the table mean above. 


\section{TABLE 2}

(Continued)

\section{Panel B: Solo Effort ${ }^{\mathrm{c}}$}

Mean $^{\mathrm{d}}$

(Standard Deviation)

Sample Size

\begin{tabular}{|c|c|c|}
\hline & \multicolumn{2}{|c|}{$\begin{array}{c}\text { Team Identity - Weak } \\
\text { Individual Compensation }\end{array}$} \\
\hline & Flat & Performance-based \\
\hline \multicolumn{3}{|l|}{ Team Compensation } \\
\hline \multirow[t]{3}{*}{ Flat } & 4.8102 & 28.7454 \\
\hline & $(9.5015)$ & (12.9941) \\
\hline & $\mathrm{n}=12$ & $\mathrm{n}=12$ \\
\hline \multirow[t]{6}{*}{ Performance-based } & 20.3426 & 39.7222 \\
\hline & $(5.6516)$ & (16.4297) \\
\hline & $\mathrm{n}=12$ & $\mathrm{n}=12$ \\
\hline & \multirow{2}{*}{\multicolumn{2}{|c|}{$\begin{array}{l}\text { Team Identity - Strong } \\
\text { Individual Compensation }\end{array}$}} \\
\hline & & \\
\hline & Flat & Performance-based \\
\hline \multicolumn{3}{|l|}{ Team Compensation } \\
\hline \multirow[t]{3}{*}{ Flat } & 8.1991 & 40.0833 \\
\hline & $(7.2625)$ & (17.1394) \\
\hline & $\mathrm{n}=12$ & $\mathrm{n}=12$ \\
\hline \multirow[t]{3}{*}{ Performance-based } & 24.9398 & 27.5093 \\
\hline & $(16.2313)$ & (13.7255) \\
\hline & $\mathrm{n}=12$ & $\mathrm{n}=12$ \\
\hline
\end{tabular}

${ }^{c}$ Table 2, Panel B represents 96 student participants solo effort choices in a computerized experimental game where I manipulate Team Compensation (flat, performance-based), Individual Compensation (flat, performance-based), and Team Identity (weak, strong) between subjects.

${ }^{\mathrm{d}}$ Mean is the mean of between subjects mean of the 96 participants' 18 within subjects means by condition. For example, Participant A's total solo effort is extended over 18 periods, therefore participant A's mean solo effort is his/her total solo effort divided by 18. Participant A's mean solo effort is summed with the mean solo effort choices of the other 11 participants in his/her condition and then divided by 12 (the total number of participants per condition) to arrive at the table mean above. 


\section{TABLE 2}

(Continued)

\section{Panel C: Team Effort ${ }^{\mathrm{e}}$}

\section{Mean ${ }^{\mathrm{f}}$}

(Standard Deviation)

Sample Size

Performance-based

\begin{tabular}{cc}
\multicolumn{2}{c}{ Team Identity - Weak } \\
Individual Compensation
\end{tabular}

$\underline{\text { Team Compensation }}$

Flat

$$
\begin{gathered}
10.5787 \\
(10.4385) \\
n=12
\end{gathered}
$$

22.2639

(20.3173)

$\mathrm{n}=12$
10.4352

$(7.2461)$

$\mathrm{n}=12$

26.8194

(13.7902)

$\mathrm{n}=12$

${ }^{\mathrm{e}}$ Table 2, Panel C represents 96 student participants team effort in a computerized experimental game where I manipulate Team Compensation (flat, performance-based), Individual Compensation (flat, performance-based), and Team Identity (weak, strong) between subjects.

fMean is the mean of between subjects mean of the 96 participants' 18 within subjects means by condition. For example, Participant A's total team effort is extended over 18 periods, therefore participant A's mean team effort is his/her total team effort divided by 18. Participant A's mean team effort is summed with the mean team effort choices of the other 11 participants in his/her condition and then divided by 12 (the total number of participants per condition) to arrive at the table mean above. 


\section{Replication Tests}

To confirm prior research, I examine the relationships between the manipulated variables (team identity, individual compensation, and team compensation) and performance and expect to find positive relationships between each. Table 3 presents ANOVA results by dependent variable. Consistent with prior literature, which shows performance-based compensation positively affects effort and performance, the results confirm that team performance-based compensation (Team) positively affects output (F $=90.288, \mathrm{p}=0.000)$, solo effort $(\mathrm{F}=8.307, \mathrm{p}=0.005)$, and team effort $(\mathrm{F}=34.176, \mathrm{p}=$ .000). Also consistent with prior performance-based compensation literature, the results show that individual performance-based compensation (Indiv) positively affects output $(\mathrm{F}=29.804, \mathrm{p}=0.000)$ and solo effort $(\mathrm{F}=53.390, \mathrm{p}=0.000)$. However, no relationship is found between individual performance-based compensation and team effort $(F=0.146, p=0.703)$.

Team identity ANOVA results are also consistent with prior research which suggests that stronger team identity results in more effort and better performance. Team identity (ID) positively affects output $(\mathrm{F}=19.665, \mathrm{p}=0.000)$ and team effort $(\mathrm{F}=8.783$, $\mathrm{p}=0.004)$. Results indicate no relationship between team identity (ID) and solo effort $(\mathrm{F}=0.446, \mathrm{p}=0.506)$ 
TABLE 3

Results from Three ANOVAs with Repeated Measures ${ }^{\mathrm{a}}$

\begin{tabular}{|c|c|c|c|c|c|c|c|c|c|}
\hline \multirow{3}{*}{$\frac{\text { Source }}{\text { Intercept }}$} & \multicolumn{3}{|c|}{ Output } & \multicolumn{3}{|c|}{ Solo Effort } & \multicolumn{3}{|c|}{ Team Effort } \\
\hline & \multicolumn{2}{|c|}{$\underline{\text { F-statistic (df) }}$} & \multirow{2}{*}{$\frac{p \text {-value }}{0.000}$} & \multicolumn{2}{|c|}{ F-statistic (df) } & \multirow{2}{*}{$\frac{p \text {-value }}{0.000}$} & \multicolumn{2}{|c|}{ F-statistic (df) } & \multirow{2}{*}{$\frac{p \text {-value }}{0.000}$} \\
\hline & 704.565 & $(1,88)$ & & 333.447 & $(1,88)$ & & 148.986 & $(1,88)$ & \\
\hline Team & 90.288 & $(1,88)$ & 0.000 & 8.307 & $(1,88)$ & 0.005 & 34.176 & $(1,88)$ & 0.000 \\
\hline Indiv & 29.804 & $(1,88)$ & 0.000 & 53.390 & $(1,88)$ & 0.000 & 0.146 & $(1,88)$ & 0.703 \\
\hline ID & 19.665 & $(1,88)$ & 0.000 & 0.446 & $(1,88)$ & 0.506 & 8.783 & $(1,88)$ & 0.004 \\
\hline Team $\times$ Indiv & 10.623 & $(1,88)$ & 0.002 & 10.127 & $(1,88)$ & 0.002 & 0.179 & $(1,88)$ & 0.673 \\
\hline Team $\times$ ID & 3.141 & $(1,88)$ & 0.080 & 4.407 & $(1,88)$ & 0.039 & 0.052 & $(1,88)$ & 0.820 \\
\hline Indiv $\times$ ID & 0.005 & $(1,88)$ & 0.941 & 0.693 & $(1,88)$ & 0.407 & 0.327 & $(1,88)$ & 0.569 \\
\hline Team $\times$ Indiv $\times$ ID & 1.332 & $(1,88)$ & 0.252 & 5.412 & $(1,88)$ & 0.022 & 0.353 & $(1,88)$ & 0.554 \\
\hline
\end{tabular}

Where:

Output = individual output, or $M_{i}$, as computed by equation (1).

Team $=$ Team equals 1 when team compensation is performance-based and 0 when team compensation is flat.

Indiv $=$ Indiv equals 1 when individual compensation is performance-based and 0 when individual compensation is flat.

ID = ID equals 1 when the team identity condition is strong and 0 when the team identity condition is weak.

\section{Degrees of Freedom:}

The total number of participants equals 96. Therefore degrees of freedom listed above are 88 .

\section{Replication Test Results}

Team performance-based compensation (Team) positively affects output, solo effort, and team effort.

Individual performance-based compensation (Indiv) positively affects output and solo effort.

Strong team identity (ID) positively affects output and team effort.

\section{Hypothesis Test Results}

H1: Results indicate that individual compensation and team identity have no interactive effect on output or effort.

H2a \& H2b: Results indicate that team compensation and team identity have an interactive effect on output and solo effort. Results support H2b.

H3: Results indicate that team and individual compensation do have an interactive effect on output and solo effort.

H4a \& H4b: Results indicate no three-way interaction exists among team compensation, individual compensation, and team identity.

${ }^{a}$ All models are analyzed using repeated measures GLM in SPSS 15.0. 


\section{Hypotheses Tests}

Hypothesis 1 predicts that individual performance-based compensation will show a larger positive influence on performance in weak than in strong identity conditions. ANOVA results indicate an insignificant interaction between individual performancebased compensation (Indiv) and team identity (ID) $(\mathrm{F}=0.005, \mathrm{p}=0.941)$, Table 3 . Figure 5 illustrates the interaction obtained. These results suggest that while individual performance-based compensation raises performance, it does so equally under the weak and strong identity conditions. Thus, the data do not support Hypothesis 1 . The interactions between team identity and individual performance-based compensation on solo effort and team effort are also insignificant $(\mathrm{F}=0.693, \mathrm{p}=0.407$ and $\mathrm{F}=0.327, \mathrm{p}=$ 0.569 , respectively).

Hypothesis $2 \mathrm{a}$ and Hypothesis $2 \mathrm{~b}$ are competing hypotheses with hypothesis $2 \mathrm{a}$ (2b) predicting that team performance-based compensation will show a larger (smaller) positive influence on performance in strong than in weak identity conditions. ANOVA results indicate a marginally significant interaction between team performance-based compensation (Team) and team identity (ID) $(\mathrm{F}=3.414, \mathrm{p}=0.080)$, Table 3. Figure 6 
FIGURE 5

Interaction Effect between Individual Compensation and Team Identity on Estimated Mean Individual Output:

Results for Hypothesis 1

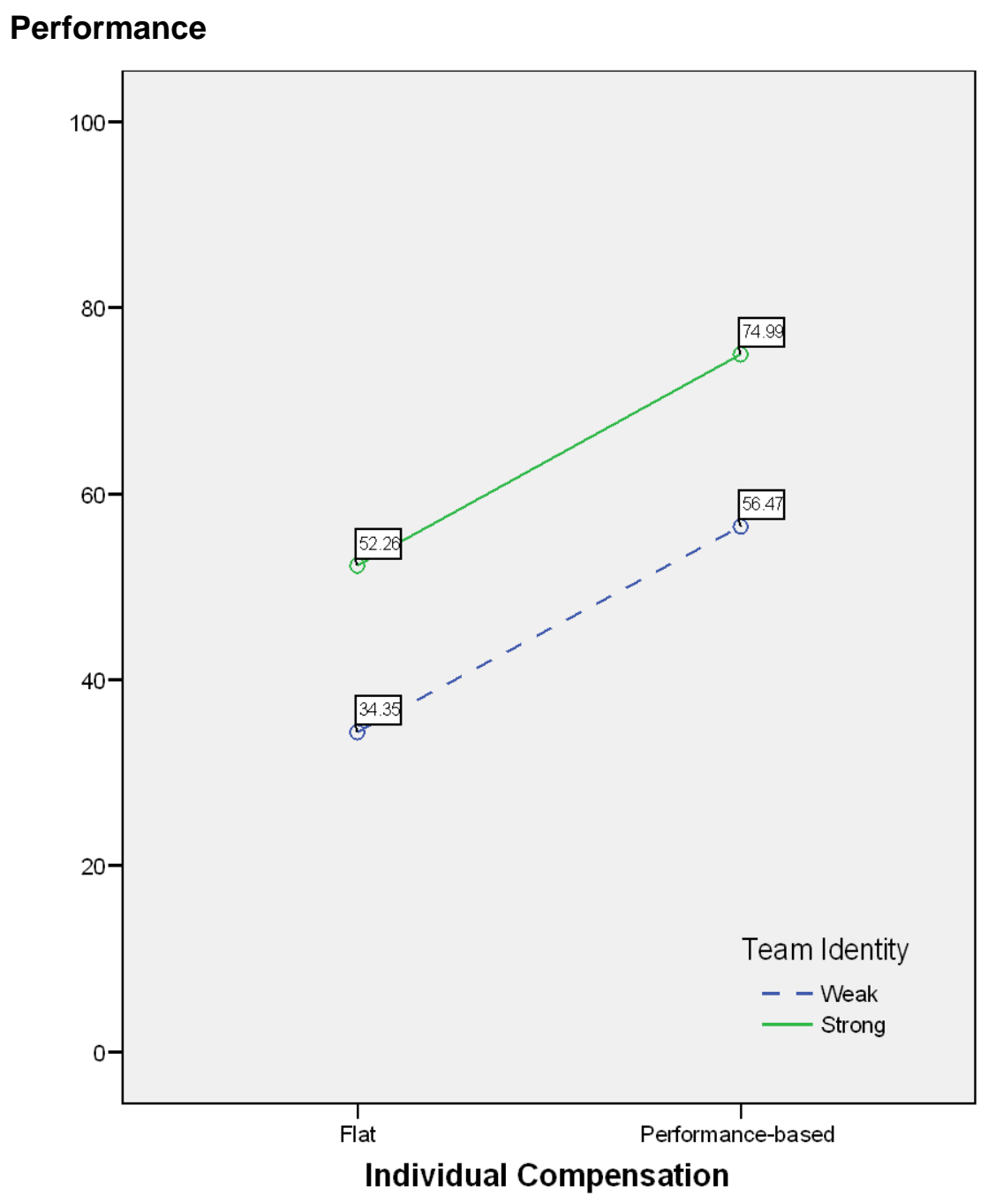

The above figure illustrates that individual compensation and team identity have no interactive effect on performance. 
illustrates the interaction obtained. The results suggest that team performance-based compensation has a larger positive influence on output in the weak than the strong identity condition, as predicted in $\mathrm{H} 2 \mathrm{~b}$. Thus, the data support the $\mathrm{H} 2 \mathrm{~b}$. As illustrated in Figure 6, when team identity is strong, the difference between flat team compensation and performance-based team compensation is less than the same difference when team identity is weak suggesting that team performance-based compensation improves performance less when team identity is strong. The interaction between team identity and team compensation on solo effort is significant $(\mathrm{F}=4.407, \mathrm{p}=0.039)$, but the same interaction on team effort is not significant $(F=0.052, p=0.820)$. The results suggest that performance-based team compensation improves solo effort more when team identity is weak, but team compensation and team identity have no interactive effect on team effort.

Hypothesis 3 predicts that output improves more when team performance-based compensation is added to individual flat compensation than when it is added to individual performance-based compensation. Results indicate a significant interaction 
FIGURE 6

Interaction Effect between Team Compensation and Team Identity on Estimated Mean Individual Output:

Hypotheses 2a and 2b



The above figure illustrates that the interaction of team compensation and team identity on performance supports $\mathrm{H} 2 \mathrm{~b}$, not $\mathrm{H} 2 \mathrm{a}$. 
between team compensation (Team) and individual compensation (Indiv) for output $(\mathrm{F}=$ 10.623, $\mathrm{p}=0.0002$ ), Table 3. Figure 7 illustrates the interaction. When individual compensation is flat, adding team performance-based compensation significantly improves output, but when individual compensation is performance-based, adding team performance-based compensation improves output to a smaller extent. The interaction effect of team and individual compensation on solo effort is significant $(\mathrm{F}=10.127, \mathrm{p}=$ 0.002), and suggests that when individual compensation is flat, adding team performance-based compensation significantly improves solo effort, but when individual compensation is performance-based, adding team performance-based compensation does not improve solo effort. The same interaction's effect on team effort is insignificant $(F=$ $0.179, \mathrm{p}=0.673)$, meaning, while team performance-based compensation improves team effort, there is no interaction effect between the compensation systems.

Hypothesis 4a predicts that when team identity is weak and individual compensation is flat, team performance-based compensation improves performance significantly, it but adds nothing when individual compensation is performance-based. However, Figure 8, Panel A shows that when team identity is weak, adding team performance-based compensation improves performance significantly regardless of the individual compensation scheme. Therefore the data do not support H4a. Specifically, Figure 8, Panel A shows that adding team performance-based compensation improves 
FIGURE 7

Interaction Effect between Team Compensation and Individual Compensation on Estimated Mean Individual Output:

Hypothesis 3

\section{Performance}

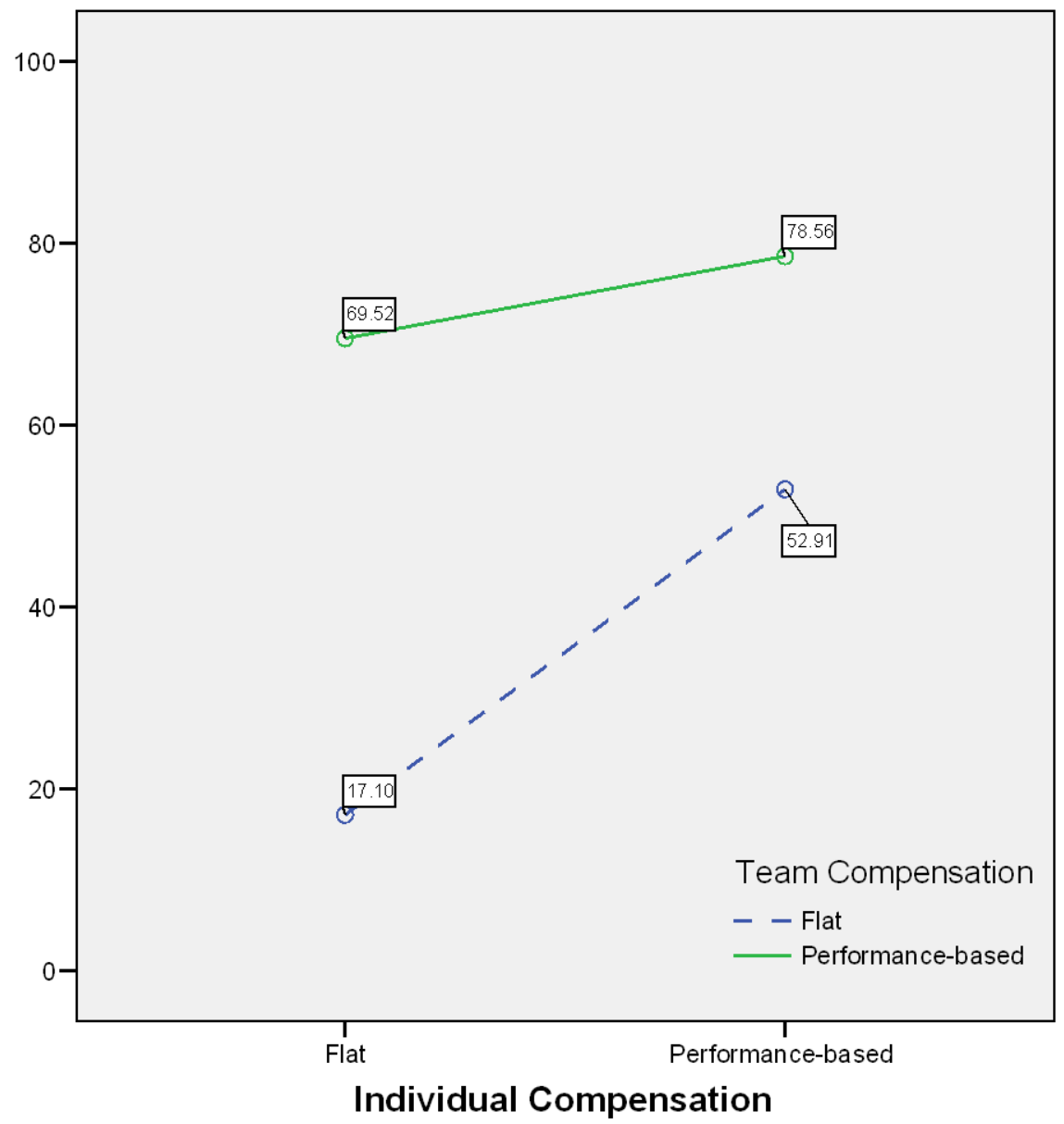

The above figure illustrates that team compensation and individual compensation have an interactive effect on performance. 
performance when individual compensation is flat more than it improves performance when individual compensation is performance-based.

Hypothesis $4 \mathrm{~b}$ predicts that when team identity is strong, team performancebased compensation improves performance about the same amount regardless of the individual compensation scheme. Figure 8, Panel B shows that adding team performance-based compensation to flat individual compensation vastly improves performance, while adding team performance-based compensation to individual performance-based compensation improves performance less. Therefore the data do not support H4b.

Together, hypotheses $4 \mathrm{a}$ and $4 \mathrm{~b}$ predict a three-way interaction among team performance-based compensation, individual performance-based compensation, and team identity, suggesting that the effectiveness of combining compensation schemes depends on the familiarity of team members. Although graphical depictions suggest a three-way interaction, ANOVA results do not support the prediction. The three-way interaction is not significant $(\mathrm{F}=1.332, \mathrm{p}=0.252)$ and neither hypothesis $4 \mathrm{a}$ nor $4 \mathrm{~b}$ is supported, Table 3. The three-way interaction among team identity, team compensation, and individual compensation is significant for solo effort $(\mathrm{F}=5.412, \mathrm{p}=0.022)$, but not for team effort $(\mathrm{F}=0.353, \mathrm{p}=0.554)$. 
Consistent with prior literature showing that strong team identity positively affects effort and performance, my results confirm that strong team identity participants are more productive than otherwise equal weak team identity participants when team compensation is flat (Figure 8). Contrast results indicate no statistically significant difference between the productivity of participants in the weak identity/ team performance-based/individual performance-based condition and those in the strong identity /team performance-based/individual performance-based condition $(\mathrm{p}=0.588)$ (see Figure 8, item 1). This result suggests that weak team identity can be overcome by offering a combination of team and individual performance-based compensation. 
FIGURE 8

Interaction between Individual and Team Compensation on Estimated Mean Individual Output by Team Identity: Hypothesis $4 a$ and $4 b$

Panel A. Graph of Results when Team Identity is Weak

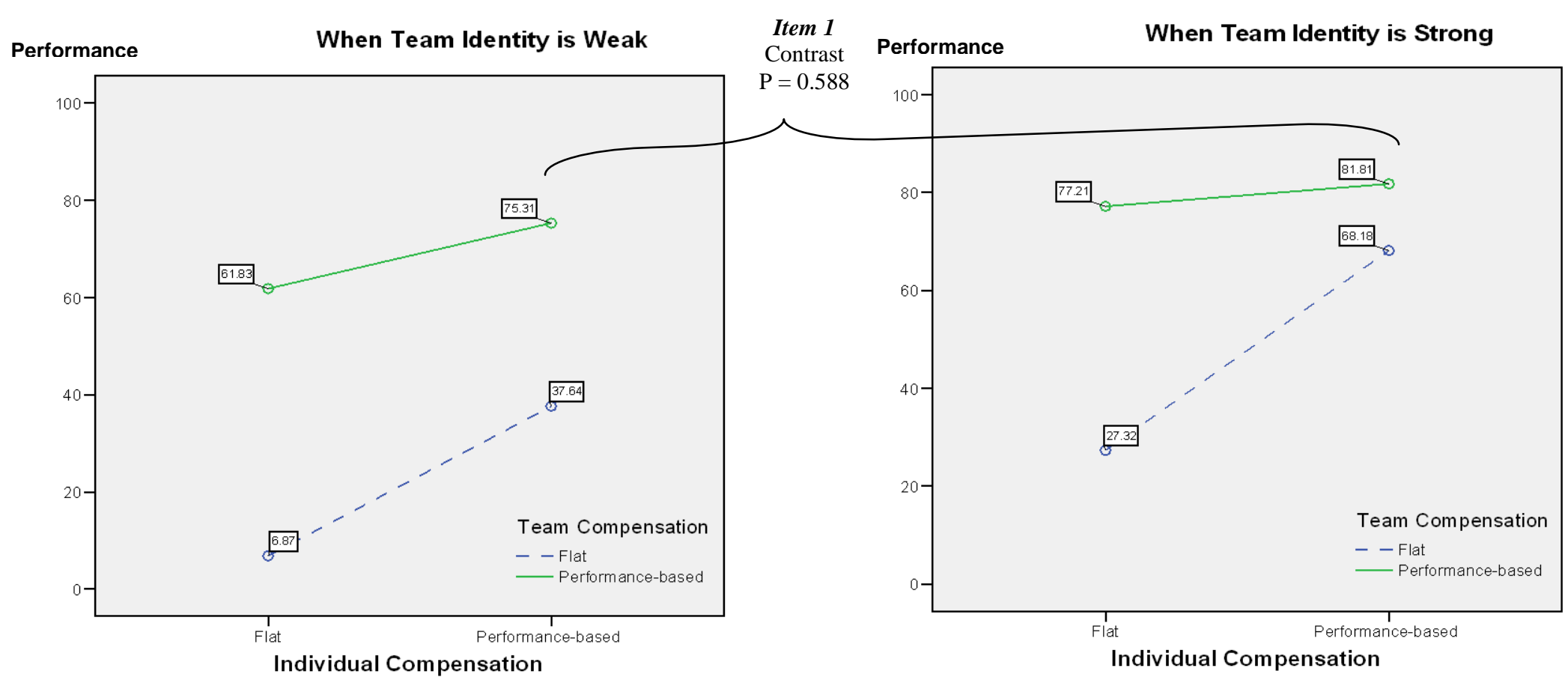

Panel B. Graph of Results when Team Identity is Strong
The above figure illustrates the interaction of team and individual compensation on performance when team identity is weak.
The above figure illustrates the interaction of team and individual compensation on performance when team identity is strong. 


\section{DISCUSSION AND CONCLUSION}

This study tests how combinations of individual compensation, team compensation, and team identity affect the effort and performance of individuals working in teams. Consistent with prior literature the results confirm that, on their own, team performance-based compensation, individual performance-based compensation, and strong team identity all positively affect performance.

Results indicate that individual performance-based compensation leads to higher solo effort and better performance, regardless of team identity. However, results also indicate that team performance-based compensation is more effective at motivating team effort and performance when team identity is weak (i.e. when teammates do not know one another). The combination of team and individual performance-based compensation results in the highest output. However, the incremental performance boost is higher from the first performance-based reward strategy, regardless of whether it is team or individual. Under both strong and weak team identity, offering both individual and team performance-based compensation results in comparable performance, which suggests that lower productivity predicted for weak team identity may be overcome with a combination of team and individual performance-based compensation regardless of teammate familiarity.

Examining the effect of both team and individual performance-based compensation extends the literature by measuring the joint effect of the two compensation schemes on performance. The results suggest that regardless of how 
closely teammates work with one another, a combination of team and individual performance-based compensation results in the best performance.

The results of this study are subject to several limitations. First, the data represent effort decisions and performance outcomes from an experimental game created to resemble one interdependent production environment, which limits the generalizability of the results. I chose to test my hypotheses using a game because it allowed me to manipulate only the variables of interest - team compensation, individual compensation, and team identity, while holding other factors (i.e., task and compensation variation) constant. Extensions of this project might examine additional production environments to confirm the results. Optimal output in this production environment is achieved with higher team effort than solo effort. Results may be weaker if optimal output is achieved with higher solo than team effort. Future non-experimental projects might also examine different levels of performance-based compensation to determine at what point performance-based compensation no longer results in better performance.

Second, participants were compensated with lottery tickets and only two tickets per session were randomly chosen for cash prizes of $\$ 40$. Non-lottery-winners were not compensated monetarily, although they did receive extra course credit. Research on the necessity of paying subjects is mixed but in experimental economics, research participants are generally paid based on their performance (Davis and Holt 1993; Friedman and Sunder 1994; Jenkins et al. 1998; Camerer and Hogarth 1999; Bonner and 
Sprinkle 2002). Finally, this experiment examined four person ad hoc teams. The results may not generalize to teams of different sizes or to permanent teams.

Solo effort, team effort, and performance are affected by the combination of compensation schemes. My results suggest that regardless of how well teammates know one another, firms can benefit from offering both team and individual performancebased compensation. However, companies should understand that the performance bump may be smaller from the second performance-based scheme. 


\section{REFERENCES}

Alchian, A., and H. Demsetz. 1972. Production, information costs, and economic organization. American Economic Review 62 (5):777-795.

Bacon, D. R., K. A. Stewart, and W. S. Silver. 1999. Lessons from the best and the worst student team experiences: How a teacher can make the difference. Journal of Management Education 23 (5):467-488.

Bacon, D. R., K. A. Stewart, and S. Stewart-Belle. 1998. Exploring predictors of student team project performance. Journal of Marketing Education 20 (1):63-71.

Banios, E. W. 1991. Teaching engineering practices. Paper presented at Frontiers in Education Conference, September 21 - 24, in West Lafayette, IN.

Bartol, K.M. and E.A. Locke 2000. Incentives and motivation. In Compensation in organizations: Current research and practice, edited by S. Rynes and B. Gerhart. San Francisco: Jossey-Bass Inc.

Bonner, S. E., and G. B. Sprinkle. 2002. The effects of monetary incentives on effort and task performance: Theories, evidence, and a framework for research. Accounting, Organizations and Society 27 (4,5):303-345.

Camerer, C. F., and R. M. Hogarth. 1999. The effects of financial incentives in experiments: a review and capital-labor-production framework. Journal of Risk and Uncertainty 19:7-42.

Chow, C. W. 1983. The effects of job standard tightness and compensation scheme on performance: An exploration of linkages. The Accounting Review 58 (4):667685.

Cohen, S. G., and D. E. Bailey. 1997. What makes teams work: Group effectiveness research from the shop floor to the executive suite. Journal of Management 23 (3):239-290.

Colbeck, C. L., S. E. Campbell, and S. A. Bjorklund. 2000. Grouping in the dark: What college students learn from group projects. The Journal of Higher Education 71 (1):60-83.

Davis, D. D., and C. A. Holt. 1993. Experimental Economics. Princeton, NJ: Princeton University Press. 
De Cremer, D., and E. van Dijk. 2002. Reactions to group success and failure as a function of identification level: A test of the goal-transformation hypothesis in social dilemmas. Journal of Experimental Social Psychology 38:435-442.

De Cremer, D., and M. van Vugt. 1999. Social identification effects in social dilemmas: A transformation of motives. European Journal of Social Psychology 29 (7):871893.

Deci, E. L., and R. M. Ryan. 1985. Intrinsic Motivation and Self-determination in Human Behavior. New York: Plenum.

DeMatteo, J. S., L. T. Eby, and E. Sundstrom. 1998. Team-based rewards: Current empirical evidence and directions for future research. Research in Organizational Behavior 20:141-183.

DeZoort, F. T., R. W. Houston, and J. T. Reisch. 2000. Incentive-based compensation for internal auditors. The Internal Auditor 57 (3):42-46.

Eckel, C. C., and P. J. Grossman. 2005. Managing diversity by creating team identity. Journal of Economic Behavior and Organization 58:371-392.

Ehrenberg, R. G., and G. T. Milkovich. 1987. Compensation and firm performance: NBER Working Paper \#2145, NBER.

Fessler, N. J. 2003. Experimental evidence on the links among monetary incentives, task attractiveness, and task performance. Journal of Management Accounting Research 15:161-176.

Fischbacher, U. 2007. z-Tree: Zurich toolbox for ready-made economic experiments. Experimental Economics 10 (2):171-178.

Fisher, J. G., S. A. Peffer, and G. B. Sprinkle. 2003. Budget-based contracts, budget levels, and group performance. Journal of Management Accounting Research 15:51-74.

Frederickson, J. R. 1992. Relative performance information: The effects of common uncertainty and contract type on agent effort. The Accounting Review 67 (4):647669.

Friedman, D., and S. Sunder. 1994. Experimental Methods: A Primer for Economists. New York, NY: Cambridge University Press.

Gary, L. 1997a. Managing a team vs. managing the individual on a team. Harvard Management Update 2 (3): 3-5. 
1997b. How to compensate teams. Harvard Management Update 2 (11): 3-6.

Goodman, P. S., and D. P. Leyden. 1991. Familiarity and group productivity. Journal of Applied Psychology 76 (44):578-586.

Gruenfeld, D. H., E. A. Mannix, K. Y. Williams, and M. A. Neale. 1996. Group composition and decision making: How member familiarity and information distribution affect process and performance. Organizational Behavior and Human Decision Processes 67 (1):1-15.

Haleblian, J., and S. Finkelstein. 1993. Top management team size, CEO dominance, and firm performance: The moderating roles of environmental turbulence and discretion. The Academy of Management Journal 36 (4):844-863.

Hilborn, R. B. 1994. Team learning for engineering students. IEEE Transactions on Education 37 (2):207-211.

Irlenbusch, B., and G. K. Ruchala. 2008. Relative rewards within team-based compensation. Labour Economics 15:141-167.

Jenkins, G. D. J., A. Mitra, N. Gupta, and J. D. Shaw. 1998. Are financial incentives related to performance? A meta-analytic review of empirical research. Journal of Applied Psychology 83:777-787.

King, R. R. 2002. An experimental investigation of self-serving biases in an auditing trust game: The effect of group affiliation. The Accounting Review 77 (2):265284.

Latane, B., K. Williams, and S. Harkins. 1979. Many hands make light the work: The causes and consequences of social loafing. Journal of Personality and Social Psychology 37:822-832.

Long, R. 2005. Group-based pay, participatory practices, and workplace performance. Paper presented at the Conference on the Evolving Workplace, September 28-29, Ottawa, Ontario.

Magjuka, R. J., and T. T. Baldwin. 1991. Team-based employee involvement programs: Effects of design and administration. Personnel Psychology 44 (4):793-812.

Nastasi, B. K., and D. H. Clements. 1991. Research on cooperative learning: Implications for practice. School Psychology Review 20 (1):110-131. 
Opdyke, J. D. 2004. Getting a bonus instead of a raise; More companies link pay to performance for broad range of employees. Wall Street Journal December 29, D1.

Peecher, M. E., and I. Solomon. 2001. Theory and experimentation in studies of audit judgments and decisions: Avoiding common research traps. International Journal of Auditing 5 (3):193-203.

Rankin, F. W. 2004. Coordinating effort under team-based and individual incentives: An experimental analysis. Contemporary Accounting Research 21 (1):191-222.

Roman, F. 2006. Effects of a team-based incentive plan on productivity, product quality, and firm performance. Working paper, Jesse H. Jones Graduate School of Management, Rice University, Houston, TX.

Rynes, S. L., B. Gerhart, and L. Parks. 2005. Personnel psychology: Performance evaluation and pay for performance. Annual Review of Psychology 56 (Feb.):571-600.

Shelley, M. K., and H. Zhao. 2007. The effects of group identification and decision disclosure on individuals' decision to incur personal cost to reduce group risk. Working paper, Mays Business School, Texas A\&M University, College Station, TX.

Sprinkle, G. B. 2000. The effect of incentive contracts on learning and performance. The Accounting Review 75 (3):299-326.

Stiffler, M. A. 2006. Move from managing to driving performance. Performance Improvement 45 (9):17-20.

Tajfel, H., and J. Turner. 1986. The social identity theory of intergroup behavior. In Psychology of Intergroup Relations, edited by S. Worchel and W. G. Austin. Chicago: Nelson-Hill, 7-24.

Towry, K. L. 2003. Control in a teamwork environment - the impact of social ties on the effectiveness of mutual monitoring contracts. The Accounting Review 78 (4):1069-1096.

Van Eerde, W., and H. Thierry. 1996. Vroom's expectancy models and work-related criteria: A meta-analysis. Journal of Applied Psychology 81 (5):575-586.

Vroom, V. H. 1964. Work and Motivation. New York: Wiley. 
Watson, W., L. K. Michaelsen, and W. Sharp. 1991. Member competence, group interaction, and group decision making: A longitudinal study. Journal of Applied Psychology 76 (6):803-809.

Wech, B. A., K. W. Mossholder, R. P. Steel, and N. Bennett. 1998. Does work group cohesiveness affect individuals' performance and organizational commitment? A cross-level examination. Small Group Research 29 (4):472-494.

Welbourne, T. M., and L. R. G. Mejia. 1995. Gainsharing: A critical review and a future research agenda. Journal of Management 21 (3):559-609.

Whitehouse, K. 2005. More companies offer packages linking pay plans to performance. Wall Street Journal, December 13, B6.

Wolfe, J., and T. I. Chacko. 1983. Team-size effects on business game performance and decision-making behaviors. Decision Sciences 14 (1):121-133. 
APPENDIX A

EXPERIMENT GAME SCREEN PRINTS 


\section{Decision Making Screen}

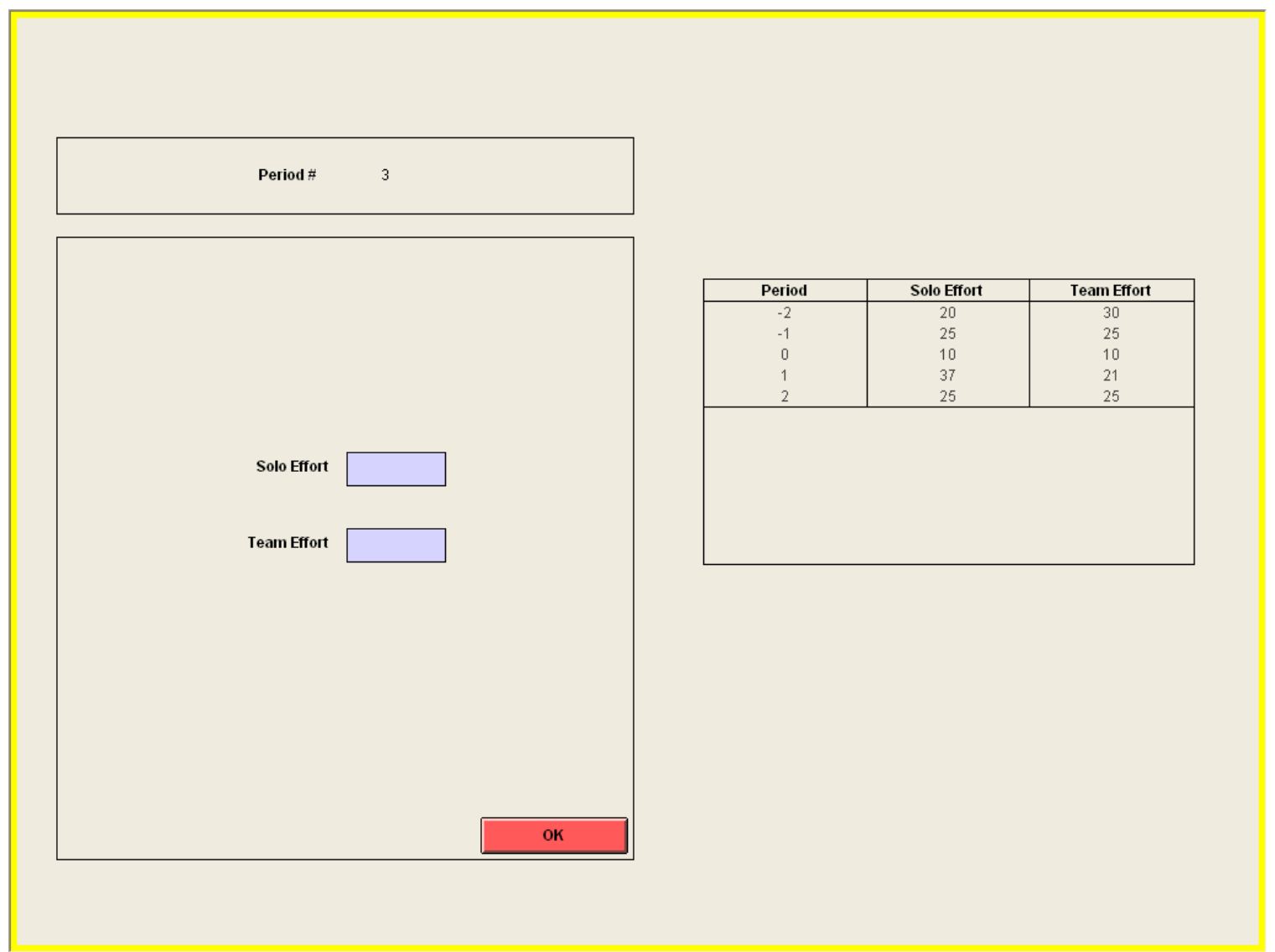

This is the $3^{\text {rd }}$ production period's decision making screen. A participant makes his/her effort decisions on the left and his/her prior period decisions are listed on the right. Nonpositive numbered periods $(-2,-1$, and 0$)$ are pre-production periods. 


\section{Recap and Compensation Screen}

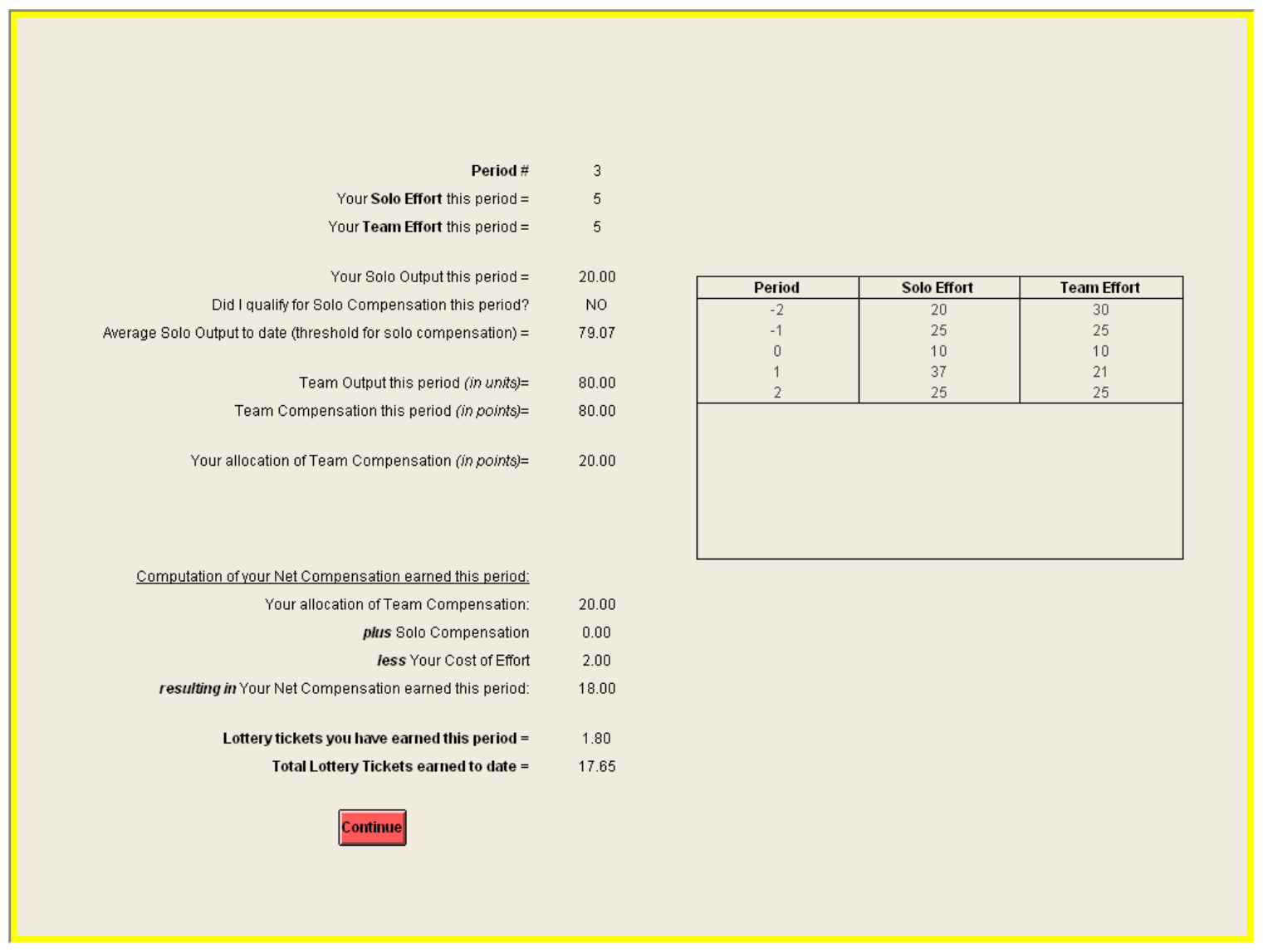

This is the $3^{\text {rd }}$ production period's recap and compensation screen. A participant views this screen after he/she has made his/her $3^{\text {rd }}$ period effort decisions. The participant's effort decisions are recapped on the top left and his/her compensation calculations are given on the bottom left. His/her prior period decisions are listed on the right. Nonpositive numbered periods $(-2,-1$, and 0$)$ are pre-production periods. The experimental condition shown above is team performance-based compensation and individual performance-based compensation. This participant did not qualify for solo compensation this period. 


\section{APPENDIX B}

EXPERIMENTAL MATERIALS - OVERVIEW 


\section{Overview}

[Strong Team ID Condition]

This is an experiment in individual team members' decision making. At the end of today's session, points will be converted into lottery tickets, 10 points $=1$ lottery ticket.

There will be two lottery drawings at the end of this session. In each lottery drawing one ticket will be randomly selected to win a cash prize of $\mathbf{\$ 4 0}$. Therefore, in this session a total of $\mathbf{\$ 8 0}$ will be distributed. An individual may win only one lottery, not both.

During this experiment you will be part of a team. Your team will be the group of 4 individuals who are seated with you. Your teammates will remain the same for the duration of the experiment.

In this experiment, your task will be to make two effort choices (pick two numbers). These effort choices will be referred to as solo effort and team effort. It will be explained in detail how these effort choices will affect both your solo output and your team output. Also we will discuss the solo, team, and net compensation which are computed in points. In addition, we will work through examples and complete a quiz to ensure that everyone understands how to calculate both output and compensation (points) before the actual decision periods begin. Actual decision periods will take place on the computer.

On the computer, you will make effort decisions in 3 practice periods (labeled periods $2,-1$, and 0 ) followed by many experiment periods. The exact number of experiment periods will be randomly determined. Different experiment sessions may play for a different number of periods. 


\section{Overview}

[Weak Team ID Condition]

This is an experiment in individual team members' decision making. At the end of today's session, points will be converted into lottery tickets, 10 points $=1$ lottery ticket.

There will be two lottery drawings at the end of this session. In each lottery drawing one ticket will be randomly selected to win a cash prize of $\mathbf{\$ 4 0}$. Therefore, in this session a total of $\mathbf{\$ 8 0}$ will be distributed. An individual may win only one lottery, not both.

During this experiment you will be part of a team of 4. Your teammates are seated randomly around the room. Your teammates will remain the same for the duration of the experiment.

In this experiment, your task will be to make two effort choices (pick two numbers). These effort choices will be referred to as solo effort and team effort. It will be explained in detail how these effort choices will affect both your solo output and your team output. Also we will discuss the solo, team, and net compensation which are computed in points. In addition, we will work through examples and complete a quiz to ensure that everyone understands how to calculate both output and compensation (points) before the actual decision periods begin. Actual decision periods will take place on the computer.

On the computer, you will make effort decisions in 3 practice periods (labeled periods $2,-1$, and 0 ) followed by many experiment periods. The exact number of experiment periods will be randomly determined. Different experiment sessions may play for a different number of periods. 


\section{APPENDIX C}

EXPERIMENTAL MATERIALS - INSTRUCTIONS 


\section{Instructions}

[Strong Team ID / Individual Flat Compensation / Team Flat Compensation Condition]

As you recall, you have been randomly assigned to a team of four. Your teammates are the individuals who are sitting with you. You will remain a member of this team of four for the remainder of the experiment even when we begin working on the computers.

\section{Effort Choices \& Cost of Effort}

At the beginning of each decision period each participant will choose two effort choices (pick two numbers). Each effort choice must be an integer from 0 to 100. Choices will be made on the computer and the screen where the data is entered will look similar to:

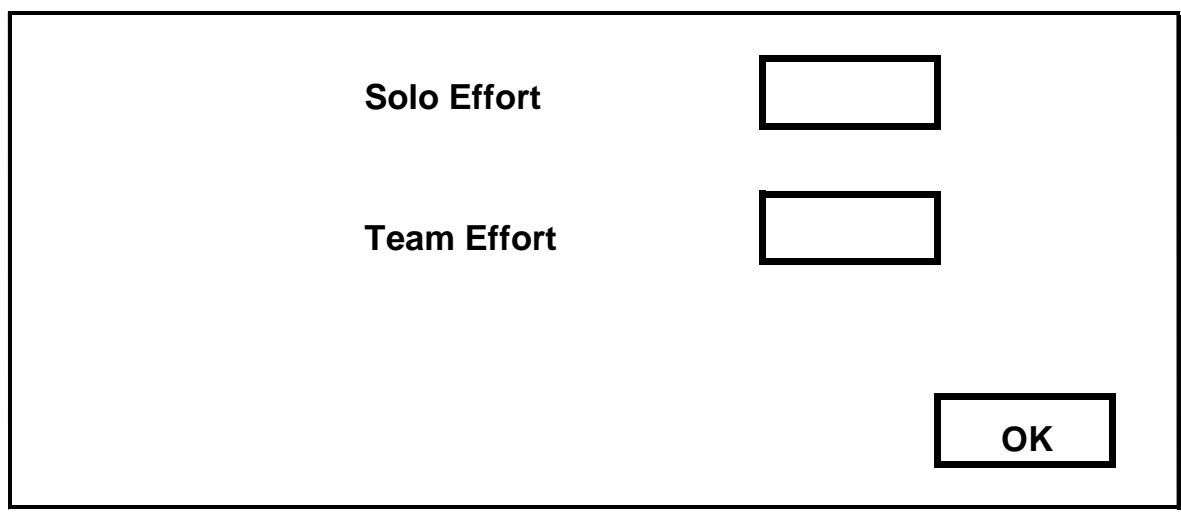

After you have made your solo effort and team effort choices for a period, you will press the OK button.

Associated with the sum of the effort choices is an effort cost. Note from the effort cost table that the higher the sum of the effort choices, the greater the associated cost. All participants have identical costs associated with their effort choices.

You will never know your teammates' effort choices and your teammates will never know your effort choices. 
Solo Output \& Solo Compensation

$\begin{array}{ll}\text { Solo Output }=\quad & \text { Your solo effort }+ \\ & {\left[3 \times\left(\text { Your solo effort }{ }^{25}\right) \times\right.} \\ & \left(\text { Teammate2's team effort }{ }^{25}\right) \times \\ & \left(\text { Teammate3's team effort }{ }^{.25}\right) \times \\ & \left.\left(\text { Teammate4's team effort }^{.25}\right)\right]\end{array}$

Your solo output depends on your solo effort and your teammates' team effort choices.

My Solo Effort \& My Teammates' Team Effort

My Solo Output

Each period you will be told the average solo output of all players to date.

Solo Compensation is set at $\mathbf{5 0}$ points per person per period.

My Solo Compensation

50 points per person
per period

\section{$\underline{\text { Team Output \& Team Compensation }}$}

Team Output $=$ Sum of ALL teammates Solo Outputs

My Solo Output + My Teammates' Solo Outputs

My Team Output

Team output takes into account all teammates' effort choices (both solo and team).

Team Compensation is set at $\mathbf{4 0 0}$ points per team per period. Your allocation or portion of team compensation will be $1 / 4$.

My Team Compensation

$$
=\begin{gathered}
400 \text { points per team } \\
\text { per period }
\end{gathered}
$$




\section{Net Compensation}

Your net compensation (in points) will be computed each period as follows:

Your allocation of team compensation

Plus any solo compensation

Less your cost of effort

\section{Lottery}

At the end of today's session, points will be converted into lottery tickets, $\mathbf{1 0}$ points = 1 lottery ticket.

There will be two lottery drawings at the end of this session. In each lottery drawing one ticket will be randomly selected to win a cash prize of $\mathbf{\$ 4 0}$. Therefore, in this session a total of $\mathbf{\$ 8 0}$ will be distributed. An individual may win only one lottery, not both.

\section{How many periods will I play?}

On the computer, you will make effort decisions in 3 practice periods (labeled periods $2,-1$, and 0 ) followed by many experiment periods. The exact number of experiment periods will be randomly determined. Different experiment sessions may play for a different number of periods. 
Example 1:

Your solo effort $=25$

Your team effort $=20$

Your teammates' solo efforts $=20,25$, and 30

Your teammates' team efforts $=10,15$, and 20

$$
\begin{aligned}
& \text { Recall: Solo Output }=\quad \text { Your Solo Effort }+ \\
& {\left[3 x\left(\text { Your Solo Effort }{ }^{25}\right) x\right.} \\
&\left(\text { Teammate2's Team Effort }{ }^{25}\right) x \\
&\left(\text { Teammate3's Team Effort }{ }^{25}\right) x \\
&\left.\left(\text { Teammate4's Team Effort }{ }^{25}\right)\right]
\end{aligned}
$$

Team Output $=$ Sum of ALL teammates Solo Outputs

Therefore, your solo output $=25+\left[3\left(25^{.25}\right)\left(10^{.25}\right)\left(15^{.25}\right)\left(20^{.25}\right)\right]=\mathbf{7 4 . 6 5}$

DON'T WORRY - the computer will do all the computations for you!!!

I want you to UNDERSTAND how it works - not actually do the computations yourself

And, your team's output (assuming your teammates' solo outputs $=75.84,78.35$, and $81.96)=74.65+75.84+78.35+81.96=\mathbf{3 1 0 . 8 0}$

Team Compensation $=\mathbf{4 0 0}$ points

Your allocation of Team compensation $=400 / 4$ or 100

Your net compensation would be:

$\begin{array}{llr}\text { Your allocation of Team Compensation: } & 100.00 \\ \text { Plus: } & \text { Solo Compensation } & 50.00 \\ \text { Less: } & \text { Your Cost of Effort } & 40.50 \\ \text { ing } & \text { Your Net Compensation } & \mathbf{1 0 9 . 5 0}\end{array}$

Resulting in: Your Net Compensation $\quad 109.50$

This is a portion of the effort cost sheet. All participants cost sheets are the same.

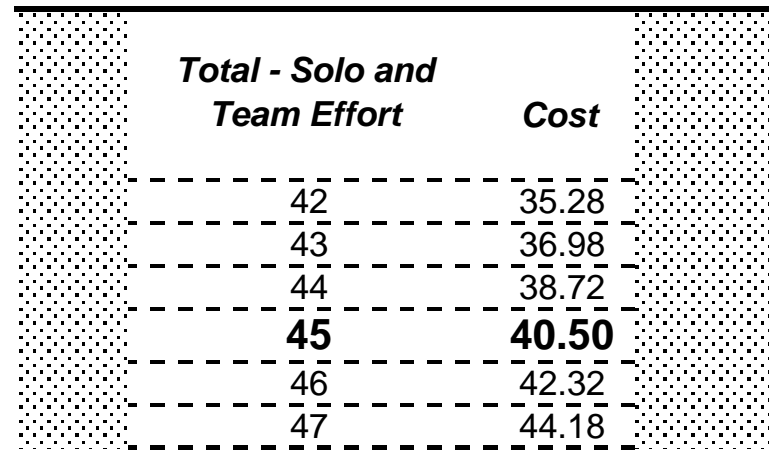


Example 2:

Your solo effort $=30$

Your team effort $=25$

Your teammates' solo efforts $=20,25$, and 30

Your teammates' team efforts $=10,15$, and 20

$$
\begin{aligned}
& \text { Recall: Solo Output }=\quad \text { Your Solo Effort }+ \\
& {\left[3 x\left(\text { Your Solo Effort }{ }^{25}\right) x\right.} \\
&\left(\text { Teammate2's Team Effort }{ }^{25}\right) x \\
&\left(\text { Teammate3's Team Effort }{ }^{25}\right) x \\
&\left.\left(\text { Teammate4's Team Effort }{ }^{25}\right)\right]
\end{aligned}
$$

Team Output $=$ Sum of ALL teammates Solo Outputs

Therefore your solo output $=30+\left[3\left(30^{.25}\right)\left(10^{.25}\right)\left(15^{25}\right)\left(20^{.25}\right)\right]=\mathbf{8 1 . 9 6}$

And, your team's output (assuming your teammates' Solo outputs $=79.04,81.41$, and $84.94)=81.96+79.04+81.41+84.94=\mathbf{3 2 7 . 3 5}$

Team Compensation $=400$ points

Your allocation of Team compensation $=400 / 4$ or 100

Your net compensation would be:

Your allocation of Team Compensation: 100.00

Plus: Solo Compensation $\quad 50.00$

Less: Your Cost of Effort $\quad 60.50$

Resulting in: Your Net Compensation $\quad 89.50$

\section{Lottery Tickets earned this period $\quad 8.95(89.50 / 10)$}

This is a portion of the effort cost sheet. All participants cost sheets are the same.

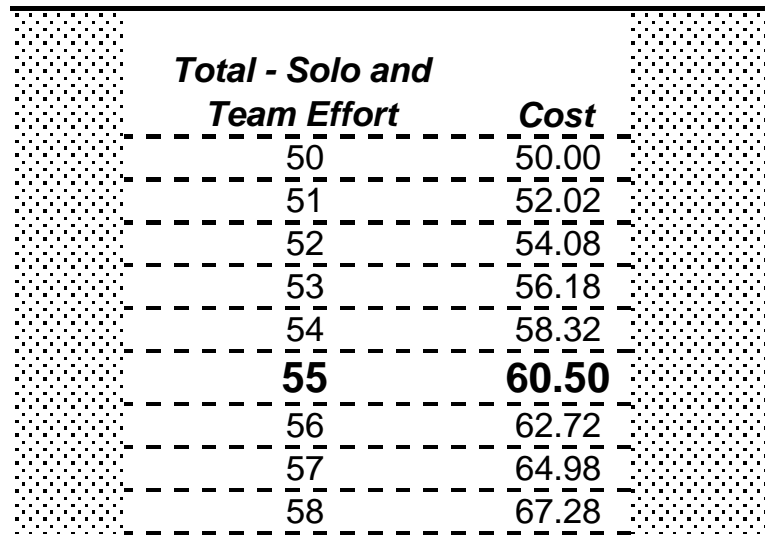




\section{Instructions \\ [Weak Team ID / Individual Performance-based Compensation / Team Performance- based Compensation Condition]}

As you recall, you have been randomly assigned to a team of four. Your teammates are seated randomly around the room. You will remain a member of this team of four for the remainder of the experiment even when we begin working on the computers.

\section{Effort Choices \& Cost of Effort}

At the beginning of each decision period each participant will choose two effort choices (pick two numbers). Each effort choice must be an integer from 0 to 100 . Choices will be made on the computer and the screen where the data is entered will look similar to:

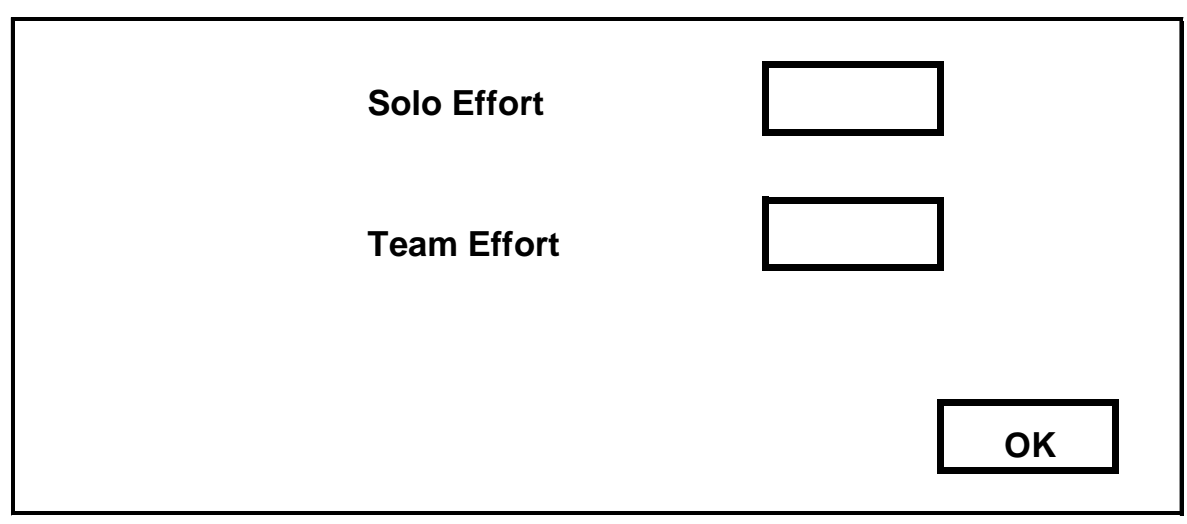

After you have made your solo effort and team effort choices for a period, you will press the OK button.

Associated with the sum of the effort choices is an effort cost. Note from the effort cost table that the higher the sum of the effort choices, the greater the associated cost. All participants have identical costs associated with their effort choices.

You will never know your teammates' effort choices and your teammates will never know your effort choices. 


\section{Solo Output \& Solo Compensation}

$\begin{array}{ll}\text { Solo output }=\quad & \text { Your solo effort }+ \\ & {\left[3 \times\left(\text { Your solo effort }{ }^{25}\right) \times\right.} \\ & \left(\text { Teammate2's team effort }{ }^{25}\right) \times \\ & \left(\text { Teammate3's team effort }{ }^{.25}\right) \times \\ & \left.\left(\text { Teammate4's team effort }^{.25}\right)\right]\end{array}$

Your solo output depends on your solo effort choice and your teammates' team effort choices.

My Solo Effort \& My Teammates' Team Effort

My Solo Output

Your qualification for solo compensation will be based on your solo output. You will earn solo compensation each period your solo output exceeds the average solo output of all players to date. When you qualify for solo compensation, your solo compensation will be equal to $50 \%$ of your allocation of team compensation.

\section{My Solo Output}

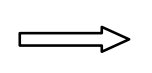

Qualifies me for Solo Compensation

\section{$\underline{\text { Team Output \& Team Compensation }}$}

Team Output $=$ Sum of ALL teammates Solo Outputs
My Solo Output + My Teammates' Solo Outputs
My Team Output

Team output takes into account all teammates' effort choices (both solo and team).

Team Compensation will be based on team output. Your team will earn points for team output, 1 output = 1 point. Since you are part of a team of four, your allocation or portion of team compensation will be $1 / 4$. 


\section{Net Compensation}

Your net compensation (in points) will be computed each period as follows:

Your allocation of team compensation

Plus any solo compensation

Less your cost of effort

\section{Lottery}

At the end of today's session, points will be converted into lottery tickets, $\mathbf{1 0}$ points = $\mathbf{1}$ lottery ticket.

There will be two lottery drawings at the end of this session. In each lottery drawing one ticket will be randomly selected to win a cash prize of $\mathbf{\$ 4 0}$. Therefore, in this session a total of $\mathbf{\$ 8 0}$ will be distributed. An individual may win only one lottery, not both.

\section{How many periods will I play?}

On the computer, you will make effort decisions in 3 practice periods (labeled periods $2,-1$, and 0 ) followed by many experiment periods. The exact number of experiment periods will be randomly determined. Different experiment sessions may play for a different number of periods. 
Example 1:

Your solo effort $=25$

Your team effort $=20$

Your teammates' solo efforts $=20,25$, and 30

Your teammates' team efforts $=10,15$, and 20

$$
\begin{aligned}
& \text { Recall: Solo Output }=\quad \text { Your Solo Effort }+ \\
& {\left[3 x\left(\text { Your Solo Effort }{ }^{25}\right) x\right.} \\
&\left(\text { Teammate2's Team Effort }{ }^{25}\right) x \\
&\left(\text { Teammate } 3 \text { 's Team Effort }{ }^{25}\right) x \\
&\left.\left(\text { Teammate4's Team Effort }{ }^{25}\right)\right]
\end{aligned}
$$

Team Output $=$ Sum of ALL teammates Solo Outputs

Therefore, your solo output $=25+\left[3\left(25^{.25}\right)\left(10^{.25}\right)\left(15^{.25}\right)\left(20^{.25}\right)\right]=\mathbf{7 4 . 6 5}$

DON'T WORRY - the computer will do all the computations for you!!!

I want you to UNDERSTAND how it works - not actually do the computations yourself

And, your team's output (assuming your teammates' solo outputs $=75.84,78.35$, and $81.96)=74.65+75.84+78.35+81.96=\mathbf{3 1 0 . 8 0}$

Team Compensation $=310.80$ points

Your allocation of Team compensation $=310.80 / 4$ or 77.70

Assuming you did not qualify for Solo compensation, your net compensation would be:

Your allocation of Team Compensation: 77.70

$\begin{array}{llr}\text { Plus: } & \text { Solo Compensation } & 0 \\ \text { Less: } & \text { Your Cost of Effort } & 40.50 \\ & & \mathbf{3 7 . 2 0}\end{array}$

Resulting in: Your Net Compensation $\quad 37.20$

This is a portion of the effort cost sheet. All participants cost sheets are the same.

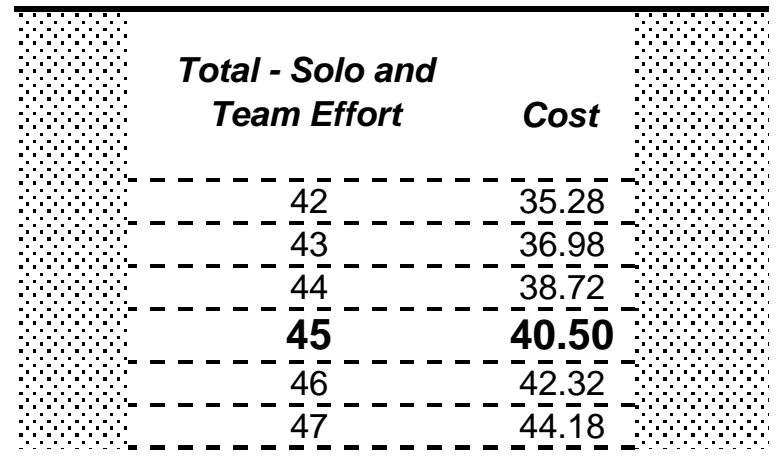


Example 2:

Your solo effort $=30$

Your team effort $=25$

Your teammates' solo efforts $=20,25$, and 30

Your teammates' team efforts $=10,15$, and 20

$$
\begin{aligned}
& \text { Recall: Solo Output }=\quad \text { Your Solo Effort }+ \\
& {\left[3 x\left(\text { Your Solo Effort }{ }^{25}\right) x\right.} \\
&\left(\text { Teammate2's Team Effort }{ }^{25}\right) x \\
&\left(\text { Teammate3's Team Effort }{ }^{25}\right) x \\
&\left.\left(\text { Teammate4's Team Effort }{ }^{25}\right)\right]
\end{aligned}
$$

Team Output $=$ Sum of ALL teammates Solo Outputs

Therefore your solo output $=30+\left[3\left(30^{.25}\right)\left(10^{.25}\right)\left(15^{25}\right)\left(20^{.25}\right)\right]=\mathbf{8 1 . 9 6}$

And, your team's output (assuming your teammates' Solo outputs $=79.04,81.41$, and $84.94)=81.96+79.04+81.41+84.94=\mathbf{3 2 7 . 3 5}$

Team Compensation $=327.35$ points

Your allocation of Team compensation $=327.35 / 4$ or 81.84

Assuming you did qualify for Solo compensation, your net compensation would be:

Your allocation of Team Compensation: 81.84

Plus: Solo Compensation 40.92

Less: Your Cost of Effort $\quad 60.50$

Resulting in: Your Net Compensation $\quad \mathbf{6 2 . 2 6}$

\section{Lottery Tickets earned this period $\quad 6.23(62.26 / 10)$}

This is a portion of the effort cost sheet. All participants cost sheets are the same.

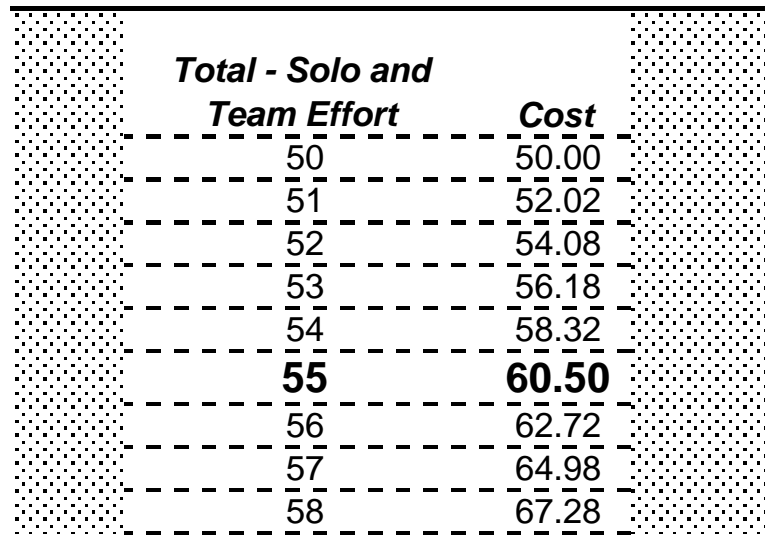


APPENDIX D

EXPERIMENT QUIZ 


\section{Quiz Questions \\ [Strong Team ID Condition] / (Weak Team ID Condition) \\ [Team Name] / (Name):}

1. My solo output will be affected by:
a. My solo effort
b. My team effort
c. My teammates' solo effort choices
d. My teammates' team effort choices
e. A \& D
f. $B \& C$
g. All of the above

2. My team output will be affected by:
a. My solo effort
b. My team effort
c. My teammates' solo effort choices
d. My teammates' team effort choices
e. A \& D
f. $B \& C$
g. All of the above

3. My team compensation (in points) will:
a. Equal team output
b. Equal my solo output
c. Always equal 400 points

4. My allocation of Team Compensation equals:
a. $100 \%$ of team compensation
b. $50 \%$ of team compensation
c. $25 \%$ of team compensation
d. $10 \%$ of team compensation

5. I will qualify for solo compensation:

a. Every period regardless of my solo output

b. Every period in which my solo output exceeds the average output to date

c. Every period in which my solo output exceeds the average output for that period 
6. [Assuming you did qualify for solo compensation, then solo compensation equals: ]

(Solo compensation equals: )

a. $10 \%$ of your allocation of team compensation

b. $50 \%$ of your allocation of team compensation

c. 10 points

d. 50 points

7. The number of lottery tickets I will receive will be affected by:

a. My allocation of team compensation plus any solo compensation received less my cost of effort

b. My allocation of team compensation less my cost of effort

c. My allocation of team compensation plus any solo compensation received

d. Regardless of allocation, compensation, and cost of effort I will receive five lottery tickets per period

Problem 1 (use the following information for questions 8 and 9):

Your solo effort $=35$

Your team effort $=17$

Your teammates' solo effort choices $=30,25$, and 20

Your teammates' team effort choices $=15,22$, and 27

8. Your solo output $=$
a. $35+\left[3\left(35^{.25}\right)\left(30^{.25}\right)\left(25^{25}\right)\left(20^{.25}\right)\right]$
b. $35+\left[3\left(35^{.25}\right)\left(15^{.25}\right)\left(22^{25}\right)\left(27^{.25}\right)\right]$
c. $17+\left[3\left(17^{.25}\right)\left(30^{.25}\right)\left(25^{25}\right)\left(20^{.25}\right)\right]$
d. $17+\left[3\left(17^{.25}\right)\left(15^{.25}\right)\left(22^{25}\right)\left(27^{.25}\right)\right]$

9. Your team output equals:

a. The sum of your solo output and your teammates' solo outputs

b. The sum of your teammates' solo outputs

c. Your solo output $\mathrm{x} 4$

d. None of the above 
Problem 2 (use the following information for question 10):

Your solo effort $=25$

Your team effort $=35$

Your teammates' solo effort choices $=30,25$, and 20

Your teammates' team effort choices $=15,22$, and 27

10. Your output $=$
e. $35+\left[3\left(35^{.25}\right)\left(30^{.25}\right)\left(25^{25}\right)\left(20^{.25}\right)\right]$
f. $35+\left[3\left(35^{.25}\right)\left(15^{.25}\right)\left(22^{25}\right)\left(27^{.25}\right)\right]$
g. $25+\left[3\left(25^{.25}\right)\left(30^{.25}\right)\left(25^{25}\right)\left(20^{.25}\right)\right]$
h. $25+\left[3\left(25^{.25}\right)\left(15^{.25}\right)\left(22^{25}\right)\left(27^{.25}\right)\right]$

Problem 3: (use the following information for questions 11 and 12)::

Your team's total compensation $=400$

Your solo effort $=20$

Your team effort $=10$

11. What is the cost associated with your total effort? Refer to the attached decision cost sheet.
a. 2
b. 8
c. 18
d. 30

12. [Assume you did qualify for solo compensation. Your net compensation (in points) equals: ]

(Your net compensation (in points) equals: )
a. $400+50-18$
b. $400+50-30$
c. $400 / 4+50-18$
d. $400 / 4+50-30$ 
APPENDIX E EXPERIMENT EXIT SURVEY 


\section{Exit Survey \\ [All Conditions]}

1. My team consisted of how many people (including you)?
a. 2
b. 3
c. 4
d. 5

2. I could point to the people on my team (circle one): True False

3. My solo output was affected by:

a. My solo effort

b. My team effort

c. My teammates' solo effort choices

d. My teammates' team effort choices

e. $A \& D$

f. $B$ \& C

g. All of the above

4. My qualifying for solo compensation depended on my solo output (Indicate the degree to which you agree/disagree)

Strongly Disagree

Agree

Strongly Agree

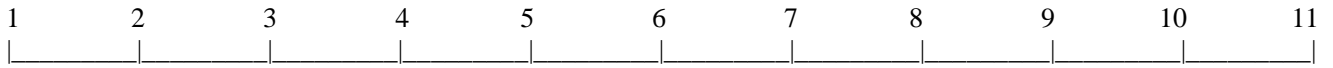

5. My team output was affected by:
a. My solo effort
b. My team effort
c. My teammates' solo effort choices
d. My teammates' team effort choices
e. $A \&$ D
f. $B$ \& C
g. All of the above

6. My team compensation depended on my team's output (Indicate the degree to which you agree/disagree)

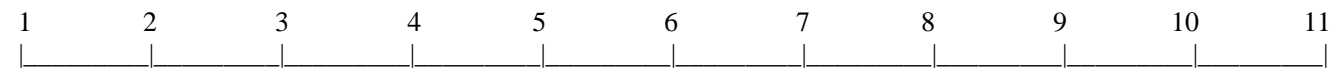


7. My NET compensation was in the form of:

a. Dollars which converted into lottery tickets

b. Francs which converted into lottery tickets

c. Points which converted into lottery tickets

d. Euros which converted into lottery tickets

8. I identified with my teammates (Indicate the degree to which you agree/disagree)

Strongly Disagree

Agree

Strongly Agree

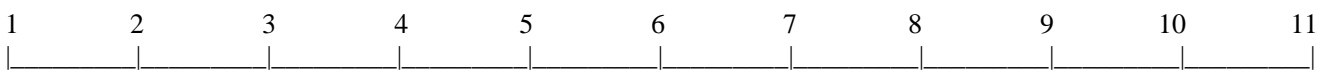

9. I was pleased to be a member of my team (Indicate the degree to which you agree/disagree)

Strongly Disagree

Agree

Strongly Agree

$\begin{array}{rrrrrrrrrrr}1 & 2 & 3 & 4 & 5 & 6 & 7 & 8 & 9 & 10 & 11 \\ \mid & \mid & \mid & \mid & \mid & \mid & \mid & \mid & \mid\end{array}$

10. I wanted my team to succeed during the experiment (Indicate the degree to which you agree/disagree)

Strongly Disagree

Agree

Strongly Agree

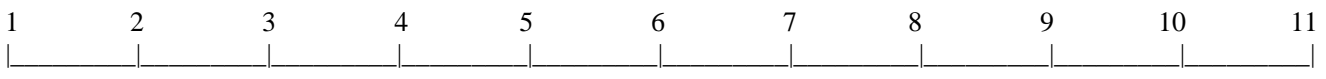

11. It bothered me to think that my team might not generate as much output as a result of effort choices (Indicate the degree to which you agree/disagree)

Strongly Disagree

Agree

Strongly Agree

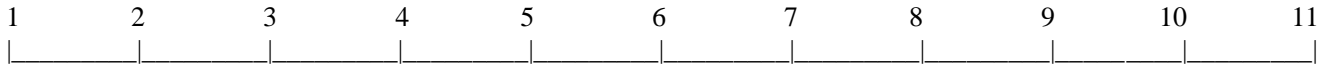

12. I was not overly concerned if my team did not generate much output because of my effort choices (Indicate the degree to which you agree/disagree)

Strongly Disagree

Agree

Strongly Agree

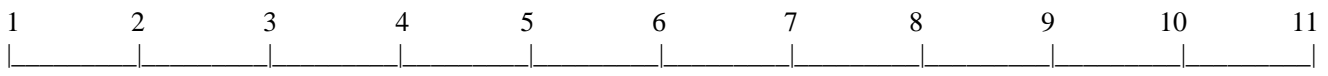


13. I attempted to maximize my points / lottery tickets (Indicate the degree to which you agree/disagree)

Strongly Disagree

Agree

Strongly Agree

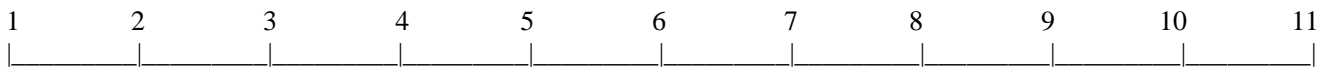

14. I felt well compensated for my time (Indicate the degree to which you agree/disagree)

Strongly Disagree

Agree

Strongly Agree

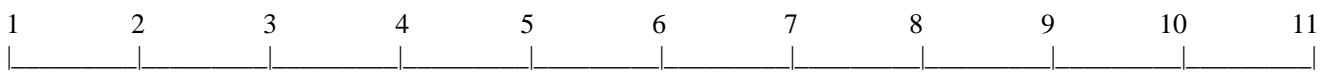

15. I was confident about my effort choices (Indicate the degree to which you agree/disagree)

Strongly Disagree

Agree

Strongly Agree

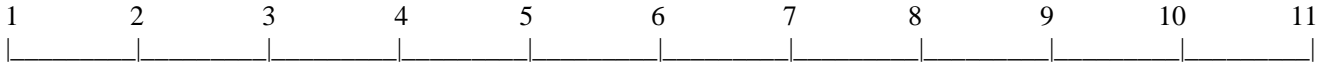

16. The scoring used in this experiment was too complicated (Indicate the degree to which you agree/disagree)

Strongly Disagree

Agree

Strongly Agree

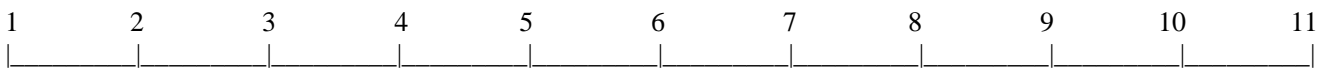

17. The computer portion of this experiment was easy to understand (Indicate the degree to which you agree/disagree)

Strongly Disagree

Agree

Strongly Agree

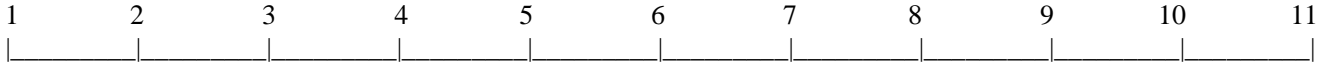

18. I understood the impact of my effort choices on my solo output (Indicate the degree to which you agree/disagree)

Strongly Disagree

Agree

Strongly Agree

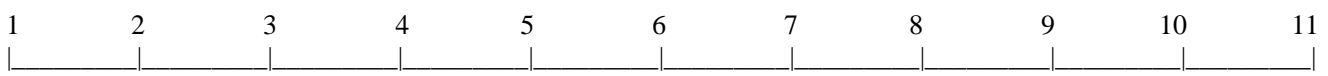


19. I understood the impact of my effort choices on my team output (Indicate the degree to which you agree/disagree)

Strongly Disagree

Agree

Strongly Agree

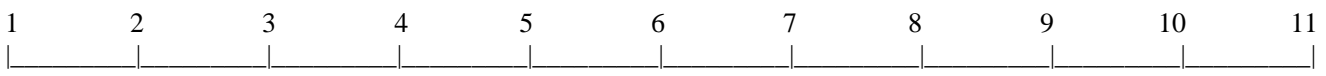

20. I understood the impact of my teammates' effort choices on my solo output (Indicate the degree to which you agree/disagree)

Strongly Disagree

Agree

Strongly Agree

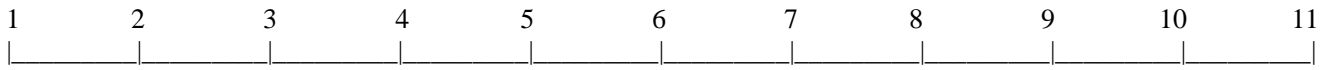

21. I understood the impact of my teammates' effort choices on my team output (Indicate the degree to which you agree/disagree)

Strongly Disagree

Agree

Strongly Agree

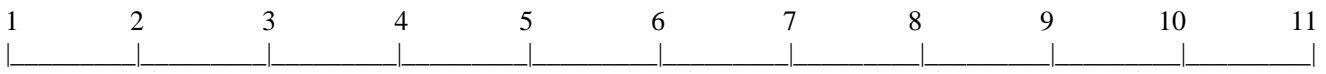

22. Please indicate your year in school (freshman, sophomore, etc.)

23. Please indicate your major (accounting, finance, marketing, etc.)

24. Please indicate how many courses you have taken previously which include group work (include courses you are taking this semester)

25. Please indicate whether you are male or female. (Check one)

Male___ Female 
26. If given a choice between the following, which would you choose (circle one per line):

$\begin{array}{lll}\$ 400 & \text { or } & 40 \% \text { chance for } \$ 1,000 \\ \$ 300 & \text { or } & 30 \% \text { chance for } \$ 1,000 \\ \$ 200 & \text { or } & 20 \% \text { chance for } \$ 1,000 \\ \$ 500 & \text { or } & 50 \% \text { chance for } \$ 1,000 \\ \$ 600 & \text { or } & 60 \% \text { chance for } \$ 1,000 \\ \$ 700 & \text { or } & 70 \% \text { chance for } \$ 1,000 \\ \$ 800 & \text { or } & 80 \% \text { chance for } \$ 1,000 \\ \$ 4,000 & \text { or } & 40 \% \text { chance for } \$ 10,000 \\ \$ 3,000 & \text { or } & 30 \% \text { chance for } \$ 10,000 \\ \$ 2,000 & \text { or } & 20 \% \text { chance for } \$ 10,000 \\ \$ 5,000 & \text { or } & 50 \% \text { chance for } \$ 10,000 \\ \$ 6,000 & \text { or } & 60 \% \text { chance for } \$ 10,000 \\ \$ 7,000 & \text { or } & 70 \% \text { chance for } \$ 10,000 \\ \$ 8,000 & \text { or } & 80 \% \text { chance for } \$ 10,000\end{array}$

Please confirm that for Question \#26 you have circled one choice PER LINE. 
Thank you for participating!

I really appreciate you taking the time to help me with this project! ? 


\section{VITA}

Name: $\quad$ Janell Leigh Blazovich, C.P.A.

Address: $\quad 7381$ Courtly Road,

Woodbury, MN 55125

Email Address: blaz7322@stthomas.edu

Education: $\quad$ B.S., Accounting, Marquette University, 1991

Master of Business Taxation, University of Minnesota, 1999

Ph. D., Accounting, Texas A\&M University, 2008 